\title{
ÁRVORES MONUMENTAIS: ANÁLISE COMPARATIVA DA LEGISLAÇÃO NACIONAL E EUROPEIA RELATIVA À PROTEÇÃO E VALORIZAÇÃO DESTE PATRIMÓNIO NATURAL
}

\author{
RAQUEL LOPES ${ }^{(1)}$, CATARINA SCHRECK REIS ${ }^{(2)}$, AMADEU M.V.M. SOARES ${ }^{(3)}$ \& PAULO RENATO \\ TRINCÃO ${ }^{(4)}$
}

Resumo:

\begin{abstract}
Atendendo à inexistência de legislação comunitária europeia, relativa à proteção das árvores monumentais, procurou-se conhecer a realidade legislativa, em vinte e três países do continente europeu. Assim, procedeu-se à análise comparativa da legislação sobre as árvores monumentais e dos critérios de classificação deste arvoredo, com base nas figuras de proteção legal existentes. Os países foram selecionados com base nos contactos internacionais estabelecidos e na pesquisa desenvolvida, considerando a sua distribuição geográfica. Atendendo à heterogeneidade da legislação existente, a mesma foi agrupada consoante o tipo de protecão jurídica em vigor. Procedeu-se, ainda, à identificação dos critérios mais representativos de classificação do arvoredo alvo de proteção por legislação, anotando-se oito classes, onde se destacam os critérios de longevidade associados a valores histórico e culturais. Foram, igualmente, analisados os inventários online existentes, em cada um dos países da amostra, tendo-se verificado a importância que estes catálogos assumem no reconhecimento público destas árvores, por vezes, monitorizadas durante décadas. O estudo contribuiu para alargar a reflexão sobre a importância que as árvores monumentais assumem a nível natural, como também para as comunidades, enquanto memória individual e coletiva do legado histórico, cultural ou paisagístico que representam. Permitiu, ainda, refletir sobre a importância que a legislação assume na preservação e salvaguarda atual e futura deste património.
\end{abstract}

Palavras-chave: árvores antigas, árvores de interesse público, legislação, critérios de monumentalidade, pesquisa comparada.

Abstract:

\begin{abstract}
Monumental Trees: comparative analysis of national and European legislation regarding the protection and enhancement of this natural heritage

Given the lack of European Community legislation on the protection of monumental trees, sought to know the legislative reality in twenty-three countries of the European continent. Thus, we proceeded to the comparative analysis of the legislation on monumental trees and the classification criteria of this grove, based on the existing legal protection figures. Countries were selected based on established international contacts and research developed considering their geographical distribution. Given the heterogeneity of existing legislation, it was grouped according to the type of legal protection in force. We also proceeded to identify the most representative criteria for the classification of trees under protection by legislation, noting eight classes, highlighting the longevity criteria associated with historical and cultural values. Existing online inventories were also analyzed in each of the sample countries, and the importance of these catalogs in the public recognition of these trees, sometimes monitored for decades, was verified. This study has contributed to a broader reflection on the importance that monumental trees assume on a natural level, as well as for communities, as an individual and collective memory of the historical, cultural or landscape legacy they represent. It also allowed to reflect on the importance that the legislation assumes in the preservation and current and future safeguard of this heritage.
\end{abstract}

Keywords: trees of public interest, legislation, criteria of monumentality, comparative research

\section{INTRODUÇ̃̃̃O}

Portugal apresenta uma das legislações mais antigas da Europa na matéria de proteção das árvores monumentais, com a proteção das "árvores nacionais", sob a guarda do Estado, em 1914 (Regulamento de proteção das árvores nacionais, aprovado pelo Decreto n. ${ }^{\circ} 682$, de 23 de julho de 1914). Esta legislação foi subsequente à criação da “Associação Protectora da Árvore" (Lei n. ${ }^{\circ} 118$, de 16 de março de 1914). Em 1938, a introdução da figura de Arvoredo de Interesse Público (Decretolei $\mathrm{n}^{\mathrm{o}} 28468 / 38$, de 15 de fevereiro) veio reforçar a importância de "proteger-se todos os arranjos flo-

\footnotetext{
(1) Departamento de Biologia e Departamento de Educação e Psicologia (Centro de Investigação em Didática e Tecnologia na Formação de Formadores, CIDTFF), Universidade de Aveiro, Campus Universitário, 3810-193, Portugal; raquellopes@ua.pt (autor correspondente)

(2) Direção do Exploratório, Centro de Ciência Viva de Coimbra, Rotunda das Lages, Parque Verde do Mondego, Santa Clara, 3041-901 Coimbra; Departamento de Ciências da Vida, Universidade de Coimbra, 3001-455 Coimbra, Portugal; catarina.reis@exploratorio.pt

${ }^{(3)}$ Departamento de Biologia \& Centro de Estudos do Ambiente e do Mar (CESAM), Universidade de Aveiro, Campus Universitário, 3810-193, Portugal; asoares@ua.pt

(4) Direção do "Exploratorio", Centro de Ciência Viva de Coimbra, Rotunda das Lages, Parque Verde do Mondego, Santa Clara, 3041-901 Coimbra; CGeo Centro de Geociências, Departamento de Ciências da Terra, Universidade de Coimbra, Pólo II Rua Sílvio Lima, 3030-790 Coimbra, Portugal; paulo.trincao@exploratorio.p
} 
restais e de jardins de interesse artístico ou histórico, e bem assim os exemplares isolados de espécies vegetais que pelo seu porte, idade ou raridade se recomenda a cuidadosa conservação" reforçandose ainda, que a "proteção que lhe for dada pelo Estado frutifique e seja seguida pelos particulares". Este diploma foi, posteriormente, atualizado pela Lei n. ${ }^{\circ} 53$, de 5 de setembro de 2012, regulamentada pela Portaria n. ${ }^{\circ} 124$, de 24 de junho de 2014, que "Estabelece os critérios de classificação e desclassificação de arvoredo de interesse público". Neste âmbito, as árvores isoladas ou em conjuntos arbóreos cujas características singulares como o porte, a idade, a raridade, a forma ou o seu significativo valor histórico, cultural, natural ou paisagístico, as permite distinguir das demais árvores da sua espécie, podem ser protegidas por legislação nacional específica e, como tal, auferir de proteção legal. O património arbóreo classificado assume assim, um estatuto similar aos Imóveis de Interesse Público. No caso português cabe, atualmente, ao Instituto de Conservação da Natureza e das Florestas (ICNF) a gestão deste património cujo inventário se encontra disponível para consulta pública no Registo Nacional do Arvoredo de Interesse Público (RNAIP; e.g. http://www2.icnf.pt/portal/florestas/ aip/arvores-mon-pt-online). Este Instituto público prevê a designação "árvores monumentais" para se referir a árvores classificadas de "Arvoredo de Interesse Público" ou outras que, embora não se encontrem classificadas e protegidas pela legislação em vigor, apresentem características particulares (LOPES et al. 2019).

\section{1 Árvores monumentais: reflexão sobre o conceito}

Tanto na literatura especializada como na linguagem corrente, é frequente encontrar-se uma variedade de termos para designar as árvores monumentais como por exemplo: monumentos vivos, árvores velhas, árvores notáveis, árvores sagradas, árvores históricas, árvores seculares, árvores centenárias, árvores gigantes, árvores singulares. Estas designações são, igualmente, frequentes para se fazer referência a árvores que, não obstante as suas características "monumentais", não se encontram classificadas e protegidas pela legislação nacional.

Para além da realidade nacional, assiste-se, igualmente, a uma diversidade de designações, como apresenta Jim (2017), que descreve sessenta epítetos usados na literatura para as árvores que atraem a atenção. No território europeu, por exemplo, na Espanha, aplicam-se os seguintes termos «árboles singulares» (DomínguEZ et al. 2010) ou «árboles monumentales» (PARÉs EsPAÑOL 2009; Moya \& Moya 2013). Em Itália, recorre-se a «alberi monumental» (LISA 2011; CANNIZZARO \& Corinto 2014), em França usa-se a expressão «arbres remarquables» (DIRAISON 2003) e em Inglaterra, usa-se o termo «ancient trees» (LONSDALE 2013; Haw 2014).

Similarmente, a nível extra europeu, registam -se outras designações que enfatizam, para além de critérios dendrométricos (e.g. dimensão), a elevada longevidade que os exemplares atingem: Big Trees, nos Estados Unidos da América (EUA) (AMERICAN FOREST 2019); Old and Precious Trees (OPT), em Macau (Government Printing Bureau 2013); Ancient - Famous Trees, na China (Zhang et al. 2017).

Outros estudos encontram-se especialmente focados no contributo ecológico das árvores com características notáveis, designando-as de large old trees (Le Roux et al. 2014; StePHENSON et al. 2014; LindenMayer 2017; LiU et al. 2019). Contudo, a definição das large old trees constitui um desafio (LiNDENMAYER \& LAURANCE 2017), uma vez que são considerados vários fatores, como os valores padrão (e.g. diâmetro à altura do peito (DAP) $>100 \mathrm{~cm}$, STAGOLl et al. 2012; DAP > 60 cm, MClntyre et al. 2015), e a idade (e.g. $\geq 200$ anos, Chambers et al. 1998; 200-300 anos, BLICHARSKA \& MIKUSIŃSKI 2014). Verifica-se, ainda, uma variação de valores entre regiões e espécies (LiNDENMAYER et al. 2013), cuja variação de critérios limita a comparação entre os vários estudos científicos (LiU et al. 2019).

\section{2 Árvores monumentais: do valor à sua salva- guarda}

Para além da manutenção do equilíbrio ecológico, ao serem as árvores que mais intervêm para a mitigação do aquecimento global (STEPHENSON et al. 2014), representarem hotspots de biodiversidade (CORNEY \& BuTLER 2007), ou funcionarem na paisagem, como corredores para a vida selvagem (LINDENMAYER et al. 2013), outros autores refletem a importância que as árvores monumentais assumem para o homem, atendendo ao seu elevado valor paisagístico, histórico e cultural (BLICHARSKA \& MikusińsKi 2014; CANNIzZARo \& CoRInTo 2014). Em algumas culturas são consideradas sagradas (DAFNi 2006; FAO \& Plan Bleu 2018), tendo os seus testemunhos e manifestações perdurado na memória individual e coletiva.

$\mathrm{Na}$ Europa, apesar da sua reconhecida importância, nos últimos 100 anos, desapareceram 80\% das árvores monumentais, bosques maduros e árvores rurais seculares (MoyA 2015a). Lindenmayer et al. (2013) realçam a necessidade das novas políticas e diretrizes de gestão refletirem o declínio global deste património natural, concluindo que só com uma legislação específica para a proteção destas árvores se consegue efetivar objetivos de conservação, sendo esse enquadramento legal determinado (quando existe) por cada país. Também Moya \& Moya (2013) referem a urgência de se tomarem medidas como a criação de uma legislação específica que confira proteção deste património arbóreo presentes nas mais emblemáticas e ameaçadas paisagens da Europa. O objetivo seria o de contribuir para a sua preservação e valorização enquanto pilar para a manutenção, melhoria e conectividade das espécies e habitats da "Rede Natura 2000" (MoYA 2015a).

Neste âmbito, Blicharska \& Mikusiński 
(2014), consideram que essas políticas se encontram sobretudo focadas no valor ecológico que as árvores apresentam, considerando ser, igualmente, relevante implicar o papel sociocultural nas políticas de gestão e conservação destas árvores. Lindenmayer et al. (2017) sumariaram as três principais recomendações para limitar as ameaças à conservação das grandes árvores antigas, sendo elas: (i) proteger as árvores existentes; (ii) reduzir o risco de mortalidade, atendendo ao impacto dos fatores de ameaça sobre a dinâmica desta categoria de árvores; e (iii) assegurar a regeneração dos exemplares existentes. Importa, assim, parar o abate e restaurar as populações onde estas árvores têm sido eliminadas (LINDENMAYER et al. 2012; 2017), promovendo, de igual modo, a melhoria do seu valor estético e de segurança (MARTINS \& TRAVASsos 2012). Segundo Blicharska \& Mikusiński (2014), as árvores devem ser consideradas enquanto elementos estruturais complexos do meio, constituindo habitats ou mesmo ecossistemas inteiros em si mesmas, ao suportar numerosas espécies, a par do valor social e cultural que representam.

As campanhas de informação e sensibilização, junto do público, sobre o valor excecional que estas árvores assumem, nomeadamente, o respeito que merecem ao fazerem parte da nossa história e cultura (LISA 2011; BLICHARSKA \& MiKUSIŃSKI 2014; Moya 2015a) e o desenvolvimento de estratégias public engagement constituem outras estratégias para a preservação das árvores monumentais. O reconhecimento deste património, em diferentes culturas, épocas e fronteiras geográficas (GolabeK \& TuKIENDORF 2002; CANNIZZARO \& CORINTO 2014; JIM 2017), tem conduzido a um crescente interesse e sensibilidade pela temática (CORNEY \& BUTler 2007; Lisa 2011; MOYA \& MoYa 2013; Haw 2014). Também a valorização turística destas árvores possibilita a criação de incentivos para a sua conservação (LINDENMAYER et al. 2017) potenciando novos destinos turísticos relacionados com o património natural (Molina et al. 2014; SÁnCHEZ \& OrTega 2016). A título de exemplo, em Espanha existem várias rotas de árvores singulares inseridas em circuitos educativos (RAMÓN FERNÁNDEZ 2018). Neste sentido, tem-se assistido à proteção legal e de cuidados especiais que estas árvores carecem, levando à criação de base de dados, em inventários oficiais e não oficiais, com o objetivo da sua gestão, proteção e divulgação (GOLABEK \& TUKIENDORF 2002; JIM 2005; ORLOWSKI \& NOWAK 2007; LISA 2011; CANNIZZARO \& CORINTO 2014; LindenMaYeret al. 2017). Este levantamento tem vindo a ser desenvolvido em vários países de continentes diferentes, como por exemplo, em Inglaterra (e.g. https:// www.treeregister.org/), nos Estados Unidos da América (e.g. https://www.americanforests.org/get -involved/americas-biggest-trees/champion-treesnational-register/), no Canadá (e.g. http:// bcbigtree.ca/), ou na Austrália (e.g. https:// www.nationalregisterofbigtrees.com.au/).

Atendendo à inexistência de uma legislação comunitária que confira proteção específica às árvores com características monumentais, importa conhecer a nível legal, como os países europeus protegem este património. Assim, tendo como base a legislação nacional (Lei n. ${ }^{\circ}$ 53, de 5 de setembro de 2012; Portaria n. ${ }^{\circ} 124$, de 24 de junho de 2014) sobre a proteção das árvores monumentais, pretendeu-se analisar a proteção legal existente a nível europeu das árvores com características monumentais, bem como comparar os critérios que permitem a sua classificação. Para o efeito, foi analisado o enquadramento legal, de vinte e três países da Europa. $\mathrm{O}$ estudo pretende contribuir para alargar a reflexão sobre a importância que as árvores monumentais apresentam, considerando a legislação sobre a temática um importante instrumento para a preservação e salvaguarda deste património. Neste sentido, desenvolveram-se esforços para analisar a legislação dos países da amostra, a partir de um contributo voluntário, para se contribuir para futuras investigações mais detalhadas sobre a temática, nomeadamente para uma coerência de procedimentos legais, inexistente, até ao momento, na totalidade do território analisado.

\section{METODOLOGIA}

\subsection{Amostra}

A escolha da amostra foi intencional, posicionando-se nas amostras não probabilísticas ou empíricas (PARDAL \& CORREIA 1995). De acordo com a pesquisa bibliográfica realizada e da resposta obtida pelos contactos estabelecidos, via correio eletrónico, foram considerados vinte e três países, que constituíram a amostra do estudo. Procurou-se, igualmente, que a amostra refletisse as situações legais mais heterogéneas possíveis (e.g. legislação específica de âmbito nacional e/ou regional; legislação sem especificidade na temática e/ou ambígua e dispersa por vários dispositivos legais; vazio legal). A amostra apurada incluiu os países com legislação e sem legislação, na matéria de proteção das árvores monumentais, nomeadamente: Portugal, Espanha, Itália, Croácia, Reino Unido, Noruega, Suécia, Dinamarca, Estónia, Letónia, França, Holanda, Bélgica, Alemanha, Áustria, Suíça, Polónia, República Checa, Eslováquia, Roménia, Bulgária, Rússia (Europeia) e Turquia (Europeia).

\subsection{Desenvolvimento do estudo}

Recorreu-se ao método de análise qualitativa, que se baseou na pesquisa bibliográfica e na análise crítica de: i) documentos legais oficiais (leis, projetos de lei, regulamentos, relatórios emitidos por órgãos governamentais) realizada com base em pesquisas online através do Google, em diferentes centros de documentação de universidades, instituições e organismos com competência nos setores em causa, quer de âmbito nacional (e.g. Instituto da Conservação da Natureza e das Florestas, ICNF), quer de âmbito europeu; ii) artigos científicos e 
publicações nacionais e estrangeiras; iii) documentos recebidos após consulta de consultores internacionais com ligação à temática, que contribuíram, voluntariamente, com a partilha de informações sobre o enquadramento legal do seu país.

A metodologia adotada foi desenvolvida a partir do método de comparação funcional (functional method) e do direito em contexto (lawin-context method), proposto por Van Hoecke (2015) para a análise de um problema social específico, o que no nosso estudo se prende com a proteção legal das árvores com características monumentais. Assim, procedeu-se à comparação, caso a caso, de aspetos específicos da lei, quer do objeto de estudo - as árvores monumentais -, quer respeitante à conservação da natureza, ou ainda de âmbito florestal, urbanístico, de paisagem ou patrimonial. Apesar do método funcional ser amplamente utilizado, tem sido alvo de reparo por assumir que os diferentes locais apresentam os mesmos problemas, o que em não se verifica em países com contextos históricos, culturais e sociais muito distintos (Van Hoecke 2015). Neste sentido, tal como preconiza o método "direito em contexto", procurou-se perceber como são as leis aplicadas no seu contexto legal, sendo a análise realizada ao conteúdo dos documentos legais. Numa primeira etapa, procedeu -se à pesquisa da legislação. Contudo, atendendo à barreira linguística, quando se verificava uma ausência de produção normativa em português, inglês, espanhol, francês ou italiano foi necessário, numa segunda etapa, consultar a informação legal junto dos parceiros internacionais para se obterem informações válidas ou para a confirmação de fontes, especialmente importante na aferição do contexto legal (aplicação do método law-in-context).

\section{Categorias de análise}

A produção legal dos países da amostra foi sistematizada, com base na evidência das seguintes categorias de análise:

i) país: atendendo à sua distribuição geográfica no continente europeu;

ii) ano: em que o instrumento legal entrou em vigor;

iii) tipo de resposta jurídica: instrumentos legais existentes que conferem proteção às árvores monumentais; proposta de leis não promulgadas e em projeto; sem legislação específica sobre o assunto, sendo a questão enquadrada noutros instrumentos legais;

iv) âmbito da proteção: nacional, regional, municipal;

v) nome da lei/instrumento/proposta/ enquadramento;

vi) critérios: usados para a seleção das árvores monumentais;

vii) condicionalismos e restrições: em caso de danos sobre o arvoredo monumental;

viii) catálogos online: inventário de árvores monumentais.

\section{RESULTADOS}

Apresentam-se, sumariamente, os principais aspetos do enquadramento legislativo da amostra considerada constituída pelos vinte e três países localizados no continente europeu.

\subsection{Considerações gerais sobre o enquadra- mento legislativo da amostra}

A recolha de dados revelou-se eficaz. Constatou-se que existe uma preocupação para a necessidade de proteger as florestas antigas e as árvores monumentais contra os vários fatores de que são alvo de ameaça. Alguns países apresentam uma base jurídica que oferece direta ou indiretamente a oportunidade de proteger árvores individuais ou grupos de árvores, enquanto outros apresentam orientações vagas ou não apresentam qualquer referência à proteção deste património.

A diversidade de procedimentos legais devese, sobretudo, ao ordenamento jurídico vigente em cada Estado e, no caso dos países pertencentes à União Europeia (19 países da amostra), resulta da ausência de uma legislação comunitária específica que forneça orientações para a proteção das árvores monumentais. Esta observação é objeto de referência em vários estudos, como os de Jones et al. (2018), que justificam a importância de se criar uma lei comum para a uniformização da inventariação, proteção e implementação de medidas restritivas e sancionatórias, que confira proteção legal às árvores monumentais do espaço comunitário.

Os países analisados com as figuras legislativas mais antigas relativas à proteção específica de árvores com características monumentais são: Portugal (1914), República Checa (1920), França (1930), Áustria (1935) e Itália (1939). A Bulgária (2017) e o Reino Unido (2018) apresentam a legislação mais recente, nesta matéria.

Dentro da amostra considerada foi possível agrupar cinco tipos principais de resposta jurídica (Tabela 1 e 2). Salienta-se a legislação, atualmente em vigor, em Portugal, Itália e na Comunidade Autónoma de Valência, em Espanha, atendendo à sua especificidade, contendo critérios claros, abrangentes e profícuos para o processo de classificação das árvores monumentais. Estes territórios destacam-se, ainda, pela base jurídica bastante desenvolvida e objetiva, no âmbito da proteção e conservação das árvores monumentais, podendo até servir de referência, atendendo aos atuais desafios que este património natural enfrenta. Em Portugal, a legislação, desde a entrada em vigor, teve abrangência nacional sofrendo atualizações nos anos mais recentes. Em Itália, nas últimas décadas, o debate cultural conduziu à produção de legislação regional para a proteção das árvores monumentais assistindo-se a uma diversidade de enquadramento jurídicos (regiões com e sem legislação). Em 2013, o quadro legislativo foi fortalecido com a uniformização e alargamento da legislação a todo o território italiano dando diretrizes claras para o recenseamento das árvores monumentais e, entre 
outros procedimentos, uniformizou os critérios de seleção dessas árvores (Legge 14 gennaio 2013, n. 10 Norme per lo sviluppo degli spazi verdi urbani; CARAMiello \& Grossoni 2004; VANNUCCINI et al. 2006). Em Espanha, a nível nacional, assiste-se a uma diversidade legislativa, no que diz respeito à matéria da proteção das árvores monumentais. Contudo, nos últimos anos, o Modelo da Ordenanza Municipal de Protección de Arbolado Monumental de Intéres Local, baseado na Lei 7/1985 de Bases de Regime Local, em vigor na Comunidade Autónoma de Valência tem sido adotado em mais de 100 municípios das Comunidades Autónomas, por ser considerado um documento facilitador e uniformizador da proteção das árvores singulares (Moya \& Moya 2013; IMELSA 2014; Moya 2015b). Outros países, com uma diversidade de documentos legais, ao nível das suas regiões
(Suíça), municípios (Holanda, Letónia, Noruega) e cidades (Alemanha) poderão seguir o exemplo de Espanha e Itália, onde a necessidade de uniformizar a legislação em todo o território conduziu ao desenvolvimento de uma legislação única.

Em doze países analisados a legislação em vigor não é específica, embora esteja diretamente relacionada com a proteção das árvores monumentais, sendo estas enquadradas nos designados "monumentos naturais" (e.g. República Checa, Áustria, Eslováquia, Letónia, Alemanha, Polónia e Bélgica) ou nos "objetos naturais" (Estónia). Estas figuras legislativas incluem, para além das árvores isoladas ou conjuntos arbóreos, outros elementos naturais (e.g. afloramentos rochosos, minerais, fósseis, grutas, cascatas). As árvores são protegidas devido à sua importância ecológica ou como parte integrante de uma área protegida (e.g. jardins históricos, flo-

Tabela 1: Tipo de resposta jurídica dos países da amostra [Type of legal response from sample countries].

\begin{tabular}{|c|c|c|c|}
\hline \multirow{5}{*}{ Com legislação } & \multirow{3}{*}{ Específica } & Nacional & $\begin{array}{l}\text { Portugal }^{+} \\
\text {Itália }^{+}\end{array}$ \\
\hline & & Regional & Espanha $^{+}$ \\
\hline & & Municipal & $\begin{array}{l}\text { Suíça } \\
\text { Holanda }^{+} \\
\text {Letónia }^{+}\end{array}$ \\
\hline & $\begin{array}{l}\text { Não específica, mas } \\
\text { diretamente relacionada }\end{array}$ & Nacional & $\begin{array}{l}\text { Reino Unido }^{+} \\
\text {Turquia } \\
\text { Suécia }^{+} \\
\text {Bulgária }^{+} \\
\text {República Checa }^{+} \\
\text {Eslováquia }^{+} \\
\text {Estónia }^{+} \\
\text {Alemanha }^{+} \\
\text {Áustria }^{+} \\
\text {Bélgica }^{+} \\
\text {Polónia }^{+} \\
\text {Noruega }^{+}\end{array}$ \\
\hline & $\begin{array}{l}\text { Não específica e indireta- } \\
\text { mente relacionada }\end{array}$ & Nacional & $\begin{array}{l}\text { França }^{+} \\
\text {Dinamarca }^{+}\end{array}$ \\
\hline \multirow{2}{*}{ Sem legislação } & $\begin{array}{l}\text { Programas Nacionais } \\
\text { Estatais }\end{array}$ & Nacional & Rússia \\
\hline & \multicolumn{2}{|l|}{ Outros } & $\begin{array}{l}\text { Roménia }^{+} \\
\text {Croácia }^{+}\end{array}$ \\
\hline
\end{tabular}

Tabela 2:Enquadramento legislativo e proteção conferida às árvores monumentais nos países da amostra [Legislative framework and protection of monumental trees in sampled countries].

\begin{tabular}{|c|c|c|c|c|}
\hline \multirow{2}{*}{ Países } & \multirow{2}{*}{$\begin{array}{l}\text { Ano da } \\
\text { primeria } \\
\text { legislação }\end{array}$} & \multirow{2}{*}{$\begin{array}{l}\text { Designação } \\
\text { dada à figu- } \\
\text { ra de Árvore } \\
\text { Monumental }\end{array}$} & \multirow{2}{*}{$\begin{array}{l}\text { Proteção } \\
\text { prioritária }\end{array}$} & Legislação \\
\hline & & & & Nome da legislação / Observações \\
\hline Portugal & 1914 & $\begin{array}{l}\text { Arvoredo de } \\
\text { Interesse } \\
\text { Público }\end{array}$ & Não & $\begin{array}{l}\text { Lei n. }{ }^{\circ} 118 \text {, de } 16 \text { de março de } 1914 \text { (reconhece como instituição de } \\
\text { utilidade pública a "Associação Protectora da Árvore"). URL: https:// } \\
\text { dre.pt/web/guest/pesquisa/-/search/663570/details/maximized } \\
\text { Regulamento de Proteção das Árvores Nacionais, aprovado pelo Decreto } \\
\text { n. }{ }^{\circ} 682 \text {, de } 23 \text { de julho de } 1914 \text {. URL: https://dre.pt/application/ } \\
\text { conteudo/487141 } \\
\text { O Decreto-Lei n. }{ }^{\circ} 28468 / 38 \text {, de } 15 \text { de fevereiro de } 1938 \text { (institui a figura } \\
\text { de "Árvore de Interesse Público", AIP), sendo revogado pela Lei n. } \\
\text { 53/2012, de } 5 \text { de setembro de } 2012 \text {, posteriormente regulamentada pela } \\
\text { Portaria n. }{ }^{\circ} 124 / 2014 \text {, de } 24 \text { de junho (determina os critérios e os procedi- } \\
\text { mentos de classificação e de desclassificação do AIP). URL: https:// } \\
\text { dre.pt/pesquisa/-/search/25676940/details/maximized? } \\
\text { print preview=print-preview\&dreId=25345099 }\end{array}$ \\
\hline
\end{tabular}




\begin{tabular}{|c|c|c|c|c|}
\hline Itália & 1939 & $\begin{array}{l}\text { Arberi } \\
\text { Monumentali }\end{array}$ & Sim & $\begin{array}{l}\text { A Lei 1479/1939 da "Proteção da Beleza Natural" (Protezione delle- } \\
\text { bellezze naturali) adota medidas de proteção das árvores (Lisa 2011; } \\
\text { Cannizzaro \& Corinto 2014). O Decreto dipartimentale prot. N.5450 del } \\
\text { 19/12/2017, publicado no Diário Oficial de 12, de fevereiro de } \\
\text { 2018, aprova a primeira lista das árvores monumentais de Itália, elabora- } \\
\text { da de acordo com o artigo } 7^{\circ} \text { da Lei n. 10, de } 14 \text { de janeiro de } 2013 \\
\text { (Norme per lo sviluppo degli spazi verdi urbani). URL: http:// } \\
\text { www.minambiente.it/sites/default/files/archivio/normativa// } \\
\text { legge_14_01_2013_10.pdf } \\
\text { Proteção prioritária de árvores que alberguem espécies protegidas: i) } \\
\text { Diretiva Habitats } 43 / 93 \text { da União Europeia; ii) IUCN; iii) que constituam } \\
\text { o habitat para os insetos saproxílicos. URL: https:// } \\
\text { www.politicheagricole.it/flex/cm/pages/ServeBLOB.php/L/IT/ } \\
\text { IDPagina/11260 }\end{array}$ \\
\hline Espanha & 2006 & $\begin{array}{l}\text { Árboles } \\
\text { Monumenta- } \\
\text { les; Árboles } \\
\text { Singulares; } \\
\text { Arboles } \\
\text { Insignias }\end{array}$ & Não & $\begin{array}{l}\text { P. ex. na Comunidade de Valência: i) a Ordenanza Municipal de Protec- } \\
\text { ción de Arbolado de Interés Local e a Lei } 4 / 2006 \text {, de } 19 \text { de maio, de } \\
\text { Proteccióndel Patrimonio Arbóreo Monumentale de la Comunidad de } \\
\text { Valenciana; ii) a Lei 4/2006, de } 19 \text { de maio, sobre a Protección del Patri- } \\
\text { monio Arbóreo Monumentale de la Comunidad de Valenciana (Moya \& } \\
\text { Moya 2012; IMELSA 2014; Moya } 2015 \mathrm{~b} \text { ). } \\
\text { Espanha: a Ley } N^{\circ} 42 \text { de 2007, de } 13 \text { de diciembre, del Patrimonio Natu- } \\
\text { ral y de la Biodiversidad, modificada pela Ley } N^{\circ} 33 \text { de } 2015 \text {, de } 21 \text { de } \\
\text { septiembre, protege as árboles singulares y monumentales como monu- } \\
\text { mentos naturales (artigo 33) (FAO \& Plan Bleu } 2018 \text {; Ramón Fernández } \\
2018 \text { ), sendo complementada pelo Real Decreto } N^{\circ} 556 \text { de } 2011 \text {, de } 20 \text { de } \\
\text { abril, para el desarrollo del Inventario Español del Patrimonio Natural y } \\
\text { la Biodiversidad (Ramón Fernández 2018). }\end{array}$ \\
\hline Suíça & 1979 & $\begin{array}{l}\text { Arbres re- } \\
\text { marquables } \\
\text { genevois; } \\
\text { bemer- } \\
\text { kenswerter } \\
\text { Baume } \\
\text { (árvores } \\
\text { notáveis) }\end{array}$ & Não & $\begin{array}{l}\text { Código Civil Suíço (Schweizerischen Zivilgesetzbuch, ZGB), de 1907, } \\
\text { lançou as bases para a proteção eficaz dos Monumentos Naturais } \\
\text { (Naturdenkmaler), onde se incluem as árvores importantes. } \\
\text { Lei Federal de Planeamento Espacial (Bundesgesetz uber die Raumpla- } \\
\text { nung, RPG), de } 1979 \text { confere proteção às árvores notáveis } \\
\text { (bemerkenswerter Baume) (Denzler, 1999) }\end{array}$ \\
\hline Holanda & $\begin{array}{l}\text { Varia conso- } \\
\text { ante o Mu- } \\
\text { nicípio }\end{array}$ & $\begin{array}{l}\text { Waardevolle- } \\
\text { bomen } \\
\text { (árvores } \\
\text { valiosas); } \\
\text { Monumenta- } \\
\text { lebomem } \\
\text { (árvores } \\
\text { monumen- } \\
\text { tais) }\end{array}$ & Não & $\begin{array}{l}\text { P. ex. no Município de Velsen: o plano de política da paisagem, de } 2009 \\
\text { (landschapsbeleidsplan Velsenuit 2009), culminou na moção } 27 \text { (motie } \\
27 \text { van 2010), para proteção das árvores. URL: } \\
\text { https://www.velsen.nl/sites/default/files/2013-sept } \% \\
\text { 20beleidsplanMonumentaleBomen.pdf }\end{array}$ \\
\hline Letónia & 1977 & $\begin{array}{l}\text { Dižkoki, } \\
\bar{i} \text { patnējie } \\
\text { unkultürvēs- } \\
\text { turiskie koki } \\
\text { (Monumentos } \\
\text { naturais - } \\
\text { árvores gi- } \\
\text { gantes e } \\
\text { peculiares, } \\
\text { históricas e } \\
\text { culturais) }\end{array}$ & Sim & 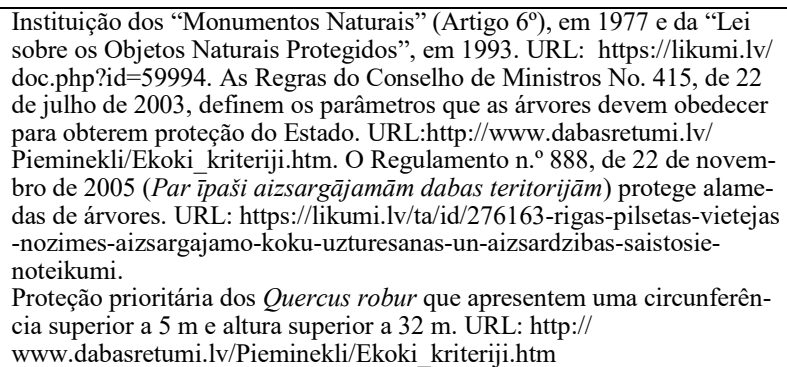 \\
\hline $\begin{array}{l}\text { Reino } \\
\text { Unido }\end{array}$ & 2018 & $\begin{array}{l}\text { Ancient } \\
\text { woodland } \\
\text { (florestas } \\
\text { antigas) }\end{array}$ & Sim & $\begin{array}{l}\text { National Planning Policy Framework (NPPF), de 2018, protege as florestas } \\
\text { antigas (ancient woodland). URL: https://www.woodlandtrust.org.uk/ } \\
\text { blog/2018/07/better-protection-for-ancient-woods-and-trees/. Não há } \\
\text { proteção específica para as árvores isoladas (ancient trees, árvores que se } \\
\text { encontram no último estágio de vida; e veteran trees, sobreviventes de } \\
\text { rigorosas condições de vida, evidenciando sinais de antiguidade, não tendo, } \\
\text { contudo, atingindo a idade das ancient trees) (Lonsdale 2013). Paralela- } \\
\text { mente ao NPPF, as Tree Preservation Order (TPO), propostas pelas autori- } \\
\text { dades locais (Local Planning Authority) permitem proteger árvores, sem } \\
\text { terem dimensões específicas ou serem particularmente antigas para auferir } \\
\text { de proteção (Corney \& Butler 2007; Lisa 2011). } \\
\text { Proteção prioritária de árvores que se encontram associadas a espécies } \\
\text { protegidas pela IUCN (e.g. morcegos), ou que adquirem o estatuto de } \\
\text { conservação "vulnerável" e de "ameaçadas" pela Wildlife \& Coutryside Act } \\
\text { (1981), sendo listadas no Livro Vermelho ou no UK Biodiversity Action } \\
\text { Plan. A árvore, enquanto habitat de espécies protegidas (Fay 2004), aufere } \\
\text { proteção contra o abate (Bengtsson 2015). Em 2018, o National Planning } \\
\text { Policy Framework (NPPF) dá ênfase ao valor das árvores nativas que } \\
\text { atingiram as últimas etapas da sua vida, enquanto habitats para a vida } \\
\text { selvagem. }\end{array}$ \\
\hline
\end{tabular}




\begin{tabular}{|c|c|c|c|c|}
\hline Turquia & 1983 & $\begin{array}{l}\text { Anıtsal } \\
\text { ağaçlar } \\
\text { (árvores } \\
\text { monumen- } \\
\text { tais) }\end{array}$ & Não & $\begin{array}{l}\text { Lei n. } .^{\circ} 2863 \text {, sobre a "Proteção da Propriedade Cultural Natural" (Kültür } \\
\text { ve Tabiat Varliklarini Koruma Kanunu) de 1983, consagra a proteção, } \\
\text { para além de outros elementos naturais, de árvores e comunidades de } \\
\left.\text { árvores de elevado interesse público (Artigo } 6^{\circ}\right) \text {. URL: https:// } \\
\text { www.avrupaanitagaclar.com/anit-ve-korunmaya-deger-agaclar- } \\
\text { projesi.html }\end{array}$ \\
\hline Suécia & 2004 & $\begin{array}{l}\text { Skyddsvärda } \\
\text { träd } \\
\text { (árvores } \\
\text { dignas de } \\
\text { proteção) }\end{array}$ & Sim & $\begin{array}{l}\text { Government program: Action Plan for Trees with High Conservation } \\
\text { Values in the Cultural and Urban Landscape (2004); e "Plano de Ação } \\
2012-2016 \text { da Agência Sueca de Proteção Ambiental". URL: http:// } \\
\text { www.naturvardsverket.se/Miljoarbete-i-samhallet/Miljoarbete-i-Sverige/ } \\
\text { Uppdelat-efter-omrade/Naturvard/Anslag-och-resultat-av-vardefull-natur } \\
\text {-/2017/Skyddsvarda-trad/. } \\
\text { Proteção prioritária através do "Plano de Ação 2012-2016 da Agência } \\
\text { Sueca de Proteção Ambiental" (Naturvårdsverket) definiu para efeitos de } \\
\text { proteção: i) carvalhos grandes, antigos e ocos (idade > } 200 \text { anos), e outras } \\
\text { árvores individuais ou em arboretos, vivas ou mortas, de meio natural e } \\
\text { urbano, atendendo ao seu valor natural, mas também, por constituírem o } \\
\text { habitat para vários seres vivos (biótopo), alguns dos quais alvo de prote- } \\
\text { ção Comunitária (Diretiva Habitats). As árvores que se encontrem exclu- } \\
\text { ídas destas áreas podem ser juridicamente protegidas a nível municipal, } \\
\text { através do } 7^{\circ} \text { capítulo do Código Ambiental (NATURVARDSVERET } \\
\text { RAPPORT 2012; Bengtsson 2015); ii) árvores de elevado valor ambien- } \\
\text { tal, cultural ou biológico quando constituam o habitat para várias espé- } \\
\text { cies de seres vivos que constem da lista vermelha de espécies ameaçadas } \\
\text { da IUCN (Bengtsson 2015). }\end{array}$ \\
\hline Bulgária & 2017 & \begin{tabular}{|l|} 
Вековни и \\
забележителни \\
дървета \\
(árvores \\
antigas e no- \\
táveis)
\end{tabular} & Não & $\begin{array}{l}\text { "Lei da Diversidade Biológica" (Biodiversity Act), de } 18 \text { de junho de } \\
\text { 2017, regulamenta, para além de outros elementos naturais, a proteção de } \\
\text { árvores (isoladas ou agrupadas) antigas e notáveis (вековни и } \\
\text { забележителни дървета) (Artigo } 109^{\circ} \text { ). URL: http:// } \\
\text { eea.government.bg/bg/legislation/biodiversity/ZBR_en_26_07_2016.pdf }\end{array}$ \\
\hline $\begin{array}{l}\text { República } \\
\text { Checa }\end{array}$ & 1920 & $\begin{array}{l}\text { Památné } \\
\text { stromy } \\
\text { (árvores } \\
\text { monumento) }\end{array}$ & Sim & $\begin{array}{l}\text { Em 1920, o Allocation Act (parágrafo 20) permitiu conservar árvores } \\
\text { monumentais a partir de uma base legislativa que considerou a relação } \\
\text { entre as pessoas, as árvores e as florestas (Úradníček et al. 2017). Act No } \\
\text { 114/1992 Gazette on the Nature and Landscape Protection (section 46). } \\
\text { URL: http://www.ochranaprirody.cz/en/legislation } \\
\text { Proteção prioritária de árvores, tanto isoladas como em grupo, desde que } \\
\text { apresentem extraordinária importância biológica, ao representarem o } \\
\text { habitat único para uma grande variedade de seres vivos. }\end{array}$ \\
\hline Eslováquia & 1955 & $\begin{array}{l}\text { Chránené } \\
\text { stormy } \\
\text { (árvores } \\
\text { protegidas) }\end{array}$ & Não & $\begin{array}{l}\text { Lei No.1/1955 sobre a "Conservação da Natureza do Estado" (Štátnej } \\
\text { Ochrane Prírody) declara as árvores enquanto "Monumento Natural } \\
\text { Protegido". A Lei do Conselho Nacional da República Eslovaca No. } \\
\text { 287/1994 Coll., relativa à "Proteção da Natureza e da Paisa- } \\
\text { gem" (Ochrane Prírody a Krajiny) consigna a proteção de árvores ou } \\
\text { grupos de árvores. Esta Lei esteve na base da nova Lei 543/2002 } \\
\text { Coll.URL: https://www.enviroportal.sk/katalog-chranenych-stromov }\end{array}$ \\
\hline Estónia & 2003 & $\begin{array}{l}\text { Florestas ou } \\
\text { grupos de } \\
\text { árvores, } \\
\text { árvores isola- } \\
\text { das }\end{array}$ & Não & $\begin{array}{l}\text { "Regulamento para a proteção de objetos naturais", de } 2003 \text { (Kaitstavate } \\
\text { looduse üksikobjektide kaitse-eeskiri). URL: https://www.riigiteataja.ee/ } \\
\text { akt/13132781?leiaKehtiv }\end{array}$ \\
\hline Alemanha & 2006 & $\begin{array}{l}\text { Naturden- } \\
\text { kamale } \\
\text { (Carvalhos, } \\
\text { Monumentos } \\
\text { Naturais } \\
\text { Nacionais da } \\
\text { Alemanha) }\end{array}$ & Sim & $\begin{array}{l}\text { "Lei Federal da Conservação da Natureza" (Novelle des Bundesnatu- } \\
\text { rschutzgesetzes), de } 1977 \text { foi ampliada em 2010, para incluir a categoria } \\
\text { dos "Monumentos Naturais Nacionais" (Nationales Naturmonument) } \\
\text { (Schlumprecht \& Kaiser 2015). URL: https://www.bmu.de/faqs/novelle- } \\
\text { des-bundesnaturschutzgesetzes/; https://www.bfn.de/themen/ } \\
\text { gebietsschutz-grossschutzgebiete/nationale-naturmonumente.html; Prote- } \\
\text { ção dos carvalhos. URL: https://www.bmu.de/themen/natur-biologische- } \\
\text { vielfalt-arten/naturschutz-biologische-vielfalt/gebietsschutz-und- } \\
\text { vernetzung/nationale-naturlandschaften/nationale-naturmonumente/ } \\
\text { Proteção prioritária dos carvalhos Ivenacker, declarados os primeiros } \\
\text { "Monumentos Naturais Nacionais da Alemanha", em Mecklemburgo- } \\
\text { Pomerânia Ocidental, a partir de } 2016 \text { (onde se inclui o maior e mais } \\
\text { antigo carvalho da Europa, com } 140 \text { m³ e } 1000 \text { anos de idade). URL: } \\
\text { https://www.bmu.de/themen/natur-biologische-vielfalt-arten/naturschutz- } \\
\text { biologische-vielfalt/gebietsschutz-und-vernetzung/nationale- } \\
\text { naturlandschaften/nationale-naturmonumente/ }\end{array}$ \\
\hline Áustria & 1997 & Árvores & Não & $\begin{array}{l}\text { "Lei de Proteção à Natureza de Reich", de 1935, consagrou a figura de } \\
\text { "Monumento Natural" (Naturdenkamale), posteriormente substituída, em } \\
\text { 1997, pela "Lei de Conservação da Natureza e Desenvolvimento Paisa- } \\
\text { gem" (Artigo 29º (Gesetzüber Naturschutzund Landschaftsentwicklung). } \\
\text { Url: https://www.ris.bka.gv.at/GeltendeFassung.wxe? } \\
\text { Abfrage=LrVbg\&Gesetzesnummer=20000466 }\end{array}$ \\
\hline
\end{tabular}




\begin{tabular}{|c|c|c|c|c|}
\hline Bélgica & Sem dados & $\begin{array}{l}\text { Merkwaar- } \\
\text { dige } \\
\text { Bomen ( } \\
\text { árvores } \\
\text { notáveis) }\end{array}$ & Não & Sem dados. \\
\hline Polónia & 2004 & $\begin{array}{l}\text { Pomnik } \\
\text { przyrody } \\
\text { (monumentos } \\
\text { naturais) }\end{array}$ & Não & $\begin{array}{l}\text { Artigo } 6^{\circ} \text { parágrafo } 1 \text { ponto } 6 \text {, art. 40, art. } 44 \text { da Lei da Conservação da } \\
\text { Natureza, de } 16 \text { de Abril de } 2004 \text {. Desde } 11 \text { de maio de 2017, vigora a } \\
\text { "Lei da Conservação da Natureza" (Ustawa o ochronie przyrody). URL: } \\
\text { http://prawo.sejm.gov.pl/isap.nsf/DocDetails.xsp?id=WDU20170001074 }\end{array}$ \\
\hline Noruega & 2011 & $\begin{array}{l}\text { Carvalhos } \\
\text { ocos }\end{array}$ & Sim & $\begin{array}{l}\text { Lei de Diversidade Natural (Forskrift om utvalgte naturtyper etter natur- } \\
\text { mangfoldloven).URL: https://lovdata.no/dokument/SF/forskrift/2011-05- } \\
\text { 13-512https://www.regjeringen.no/ } \\
\text { contentassets/80fbe7d1609d496a8f7422b991dad48a/ } \\
\text { hule_eiker_infoark_110513.pdf?id=2079173 } \\
\text { Proteção prioritária pela Diretiva Habitats: nos anos } 80 \text {, o "Registro de } \\
\text { espécies de insetos ameaçados de extinção em árvores ocas e antigas" } \\
\text { imprimiu uma maior dinâmica na monitorização de árvores ocas e anti- } \\
\text { gas. Em 2011, a introdução da "Lei da Diversidade Natural" (Forskrift } \\
\text { om utvalgte naturtyper etter naturmangfoldloven) permitiu identificar } \\
\text { cinco habitats prioritários para a conservação, que incluem tanto carva- } \\
\text { lhos ocos (com diâmetro > } 30 \mathrm{~cm} \text { ou } 95 \mathrm{~cm} \text {, dependendo da dimensão da } \\
\text { cavidade que apresentem), como ainda carvalhos mortos, desde que } \\
\text { apresentem elevado valor natural (Sverdrup-Thygeson et al. 2014; } \\
\text { Bengtsson 2015). Os carvalhos ocos figuram entre os cinco habitats } \\
\text { prioritários para a conservação. }\end{array}$ \\
\hline França & $1930-1957$ & $\begin{array}{l}\text { Arbres } \\
\text { remarquables } \\
\text { (árvores } \\
\text { notáveis) }\end{array}$ & Não & 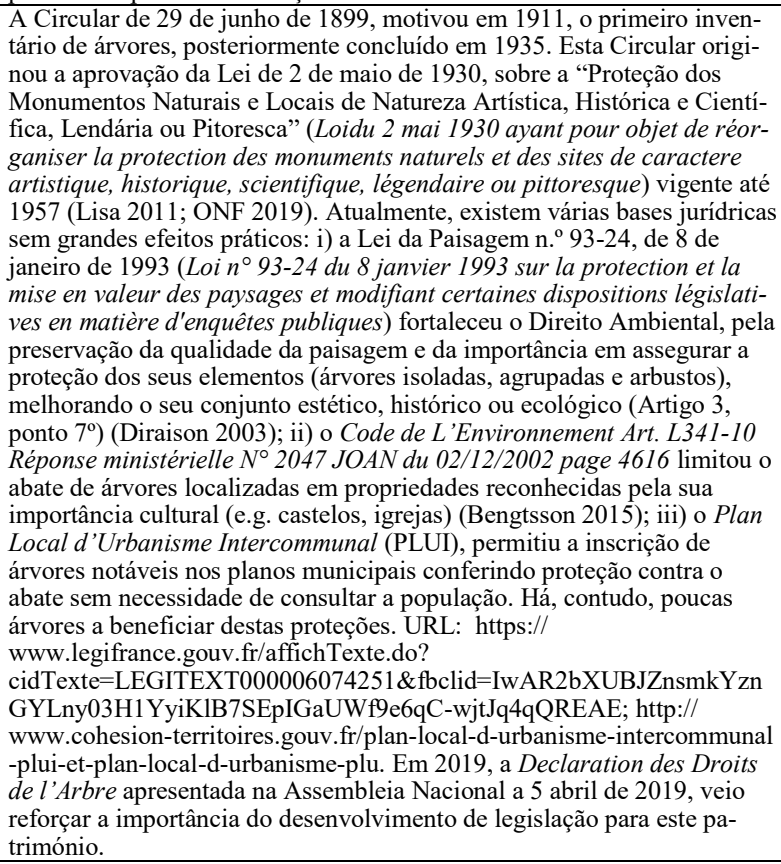 \\
\hline Dinamarca & 1917 & $\begin{array}{l}\text { Sem } \\
\text { designação } \\
\text { específica }\end{array}$ & Não & $\begin{array}{l}\text { "Lei da Conservação da Natureza", de } 2019 \text { para a proteção de ecossiste- } \\
\text { mas. As árvores que se encontrem nestas áreas são, igualmente, protegi- } \\
\text { das. Ver: https://www.retsinformation.dk/Forms/R0710.aspx?id=207969. } \\
\text { A legislação municipal de planeamento, designada por planos locais } \\
\text { ("The Planning Act"), obriga os municípios a estabelecerem disposições } \\
\text { vinculativas para uma determinada área urbana, podendo ocorrer a prote- } \\
\text { ção de árvores dentro dessa área. URL: https://www.retsinformation.dk/ } \\
\text { forms/R0710.aspx?id=200614 }\end{array}$ \\
\hline
\end{tabular}

resta, paisagem protegida, parques naturais), sobretudo de acordo com bases jurídicas relacionadas com a conservação da natureza. Apesar de na maioria dos países, a legislação produzir efeitos concretos na salvaguarda das árvores monumentais, noutros territórios, como no caso da Bélgica, são poucas as árvores protegidas a título individual, sendo essa proteção conferida através da localização da árvore numa área protegida (BENGTSSON 2015). Por exemplo, na Alemanha, apesar da legislação nacional proteger secções de paisagem ou elementos naturais como os carvalhos, na maioria das grandes cidades ( $>50.000$ habitantes) existem leis locais que prote- gem as árvores do abate, excetuando no caso de se encontrem mortas, assistindo-se a uma diversidade legislativa (MONUMENTOS NACIONAIS DA NATUREZA 2019).

Noutros países verifica-se uma legislação não específica, na matéria de proteção das árvores monumentais (e.g. França, Dinamarca, Roménia). Neste âmbito, Lindenmayer et al. (2013) e Jones et al. (2018), sugerem ser importante fortalecer a proteção das grandes árvores antigas e promover a sua regeneração, a longo prazo, para a conservação da biodiversidade nas florestas do mundo. Também os estudos de Jim \& Liu (2000) referem a necessi- 
dade urgente de aumentar a proteção deste património pelo reforço da legislação existente e a sua efetiva aplicação. Neste âmbito, similarmente, a sociedade civil é chamada a intervir no exercício da sua cidadania participativa, como ao que atualmente se assiste em França, com a pressão de especialistas e não especialistas, junto das entidades oficiais, para que a legislação sobre a proteção das árvores extraordinárias (arbres remarquables) seja reforçada, como é exemplo a proclamação da Déclaration des Droits de l'Arbre ("Declaração dos Direitos das Árvores"), na Assembleia Nacional de França, a 5 de abril de 2019, pela A.R.B.R.E.S (Arbres Remarquables: Bilan, Recherche, Études et Sauvegarde). Este movimento associativo tem dado um relevante contributo para que a proteção das árvores monumentais ganhe nova importância, neste território. $\mathrm{Na}$ realidade, assistiu-se a um retrocesso legislativo na matéria de proteção das árvores monumentais em França. Apesar da abordagem à necessidade de se protegerem árvores com dimensões impressionantes, formas específicas ou relacionadas com lendas nacionais históricas, remontar ao século XIX, a verdade é que não existe qualquer proteção específica a este arvoredo, desde 1957. Desde então, foram desenvolvidos vários dispositivos legais, mas sem grandes efeitos práticos na proteção das árvores monumentais (A.R.B.R.E.S, 2019).

A Roménia constitui outro exemplo da necessidade de se implementar uma legislação específica para a proteção das árvores monumentais (Arborii remarcabili din România), atendendo à legislação vaga, de uso pontual e com dualidade de critérios, onde só em algumas regiões se assiste à proteção deste património. Por exemplo, na mesma região, um carvalho de 400 anos de idade pode ser protegido enquanto outros, de igual valor, não (HARTEL et al. 2018). Também na Croácia ainda não foi produzida legislação para a proteção das árvores monumentais. Neste país, o "Sistema de Informação de Proteção da Natureza da República da Croácia", definido pelo artigo 196, da "Lei de Proteção da Natureza (OG 80/13, 15/18)" (Zakona o zaštitiprirode), da Agência de Ambiente e Natureza (e.g.http://www.bioportal.hr/), reúne uma base de dados temáticos de flora, fauna, habitats, áreas protegidas, espeleológico, onde não figuram as árvores monumentais.

Também se verificaram países que apesar de não apresentarem legislação, na matéria de proteção das suas árvores monumentais, têm desenvolvido esforços nesse sentido. Nomeadamente, na Federação Russa, desde 2010, o Conselho para a Conservação do Património Natural, por iniciativa da NPSA "Floresta Saudável" implementa o programa "Árvores - um monumento da vida selvagem” (Дерево - памятник живой природы ), com o apoio da Moscow Forest Forest University e da Agência Federal Florestal. Este projeto visa identificar árvores únicas de elevado valor "Monumento à Vida Selvagem" - (Памятник живой природы), em todas as regiões do país (e.g. http:// rosdrevo.ru/request/).

Em geral, dos documentos analisados, a legislação, quando existente, é clara ao referir que as árvores monumentais são entendidas como os exemplares isolados ou em grupos, de qualquer espécie, nativas ou não nativas, localizadas em áreas naturais, rurais ou urbanas, em terrenos públicos ou privados, dignas de medidas de proteção específica, tal como é referido em vários estudos (MANNING et al. 2006; CARPANETO et al. 2010; LINDENMAYERET al. 2013).

Verifica-se uma semelhança na legislação da amostra a nível geográfico, nomeadamente:

i) Europa do Sul: Portugal, Espanha, Itália, pela existência de uma legislação específica de proteção às árvores monumentais, de âmbito nacional e/ou regional;

ii) Europa do Norte: na Noruega e na Suécia com proximidade de critérios de seleção, ao conferirem proteção das árvores antigas com cavidades no tronco que proporcionam habitats a uma diversidade de espécies protegidas;

iii) Europa Ocidental: França, Holanda, Bélgica, por não apresentarem legislação específica, sendo vaga na matéria de proteção das árvores monumentais;

iv) Europa Central (Alemanha, Áustria) e Oriental (República Checa, Eslováquia, Bulgária e Rússia) como exemplos de países onde as árvores são protegidas enquanto "Monumentos Naturais" ou Programas de proteção das árvores monumentais.

\subsection{Critérios usados na seleção das árvores monumentais}

Na análise da legislação dos países selecionados, procedeu-se à identificação comparativados critérios que permitem distinguir as árvores com características monumentais das demais árvores, possibilitando um estatuto de proteção, caso exista esse enquadramento legal. Tal como nos estudos de Krebs et al. (2005), que referem a importância de selecionar as árvores monumentais segundo critérios objetivos, verificamos que, na maioria dos países, a legislação é clara e objetiva na definição dos critérios para a seleção das árvores a proteger (e.g. Portugal, Itália, Letónia, República Checa, Eslováquia) sendo protegidas, quer árvores nativas quer árvores exóticas (e.g. Portugal, Espanha, Letónia).

A tabela 3 apresenta o resultado da comparação da legislação, após uma ampla consulta. Deste modo, de acordo com a legislação analisada, as árvores monumentais são assim consideradas por reunirem um ou mais critérios que implicam a sua proteção específica para determinados valores. A este respeito, Lindenmayer (2017) considera importante, para uma conservação em grande escala e altamente direcionada, que as árvores de elevado valor (como as árvores grandes e antigas) apresentem características naturais específicas, ou mesmo, individuais. Estas reflexões convergem com os resultados da nossa investigação, atendendo à referência na legislação, em vários dos países da amostra, da "autenticidade" dos exemplares, tendo em consideração, por exemplo, a sua raridade, singularidade, valor monumental ou presença de traços únicos. Também os estudos de Schlawin \& Zahawi (2008) e de Kozlowski et al. (2012) consideram 
importante atender ao critério "raridade", uma vez que este irá permitir proteger árvores relíquias representativas de um ecossistema antigo, mas que fora destruído, sendo formado por espécies raras ou ameaçadas, que apresentam elevado valor de conservação.

Alguns países impõem limites mínimos de idade para que as árvores sejam consideradas monumentais (Espanha, Holanda, Suécia). Contudo, a idade da árvore não é considerada um critério relevante para alguns países da amostra (Reino Unido, Alemanha, Áustria, Estónia), ao contrário de outros onde, para além da idade, é dada especial importância aos parâmetros dendrométricos (e.g. Noruega, Suécia, Dinamarca e Bulgária). Na Suécia, são anotados o valor cultural, ambiental e ecológico das árvores e, na Bulgária, é dada relevância a questões fitossanitárias. Na Bélgica, de acordo com as vagas referências na legislação sobre a conservação da natureza, para além da antiguidade dos exemplares, é dada importância ao seu valor ecológico. Na Roménia, apesar de as árvores monumentais não se encontrarem salvaguardadas em legislação, a seleção destas árvores pela Organização Não Governamental (ONG) dá especial relevância às árvores antigas com elevado valor histórico e cultural.

Relativamente aos dados dendrométricos (altura, perímetro do tronco, diâmetro da copa), alguns países impõem limites mínimos que cada espécie deve apresentar (e.g. Suíça, Noruega, Suécia, Letónia, Polónia). Realça-se o exemplo da Suíça, no que diz respeito à aferição do porte das árvores propostas para classificação como árvores monumentais. $\mathrm{O}$ valor mínimo do tronco é obtido através da análise comparativa do tamanho máximo que cada espécie apresenta no seu habitat natural, bem como é aferido o tamanho que essa espécie apresenta noutros países (e.g. Grã-Bretanha, Alemanha, Itália, França). O tamanho médio é, posteriormente, comparado com o tamanho da maior árvore encontrada na cidade de Genebra, quer atendendo a registos atuais, quer a registos passados (DENZLER 1999; Perroulaz 2015).

Um conjunto de critérios transversais à maior parte da amostra prende-se com os critérios científicos, ambientais e educacionais. Neste sentido, verifica-se, uma particular referência à proteção de carvalhos (Quercus sp.), enquanto espécie de elevado valor ecológico (Alemanha, Noruega, Suécia e Letónia). Assim, para além do enquadramento legal vigente, é referida a importância de serem protegidas árvores que apresentem elevado valor ecológico, atendendo à sua especial relevância para conservação. Neste âmbito, são alvo de proteção prioritária as árvores que constituam um reservatório genético ou que se encontrem associadas a plantas e a animais raros (Bengtsson 2015), proporcionando os habitats naturais para as espécies ameaçadas da Diretiva Comunitária "Habitats" (92/43/CEE) (Itália, Suécia, República Checa, Noruega), ou que constem da Lista Vermelha da União Internacional para a Conservação da Natureza e dos Recursos Naturais (IUCN) (Itália, Reino Unido, Suécia). Contudo, apesar de vários autores considerarem a Diretiva "Habitats" um importante meio para se efetivar a proteção das árvores monumentais no espaço Comunitário (BLICHARSKA \& MiKUSIŃSKI 2014; MOYA 2015b), a mesma não é aplicada para este propósito nos países da amostra que integram a União Europeia. A título de exemplo, na Bélgica, a legislação sobre os danos à natureza é vaga, assim como a referência à proteção dos habitats de espécies protegidas, como aqueles que as árvores antigas apresentam (BENGTSSON 2015).

Outra opção, tal como referem Lindenmayer et al. (2013), seria criar um caminho político para a proteção de grandes árvores antigas, listando determinadas espécies no Apêndice II do "Comércio Internacional de Espécies da Fauna e da Flora Selvagem Ameaçadas de Extinção" (CITES), com base na importância que assumem para o ecossistema e no impacto que têm para a biodiversidade do comércio da sua madeira. Esta questão é sobretudo importante nos países onde a desflorestação das florestas antigas, pela exploração madeireira, constituiu uma ameaça real (e.g. Polónia), ou nos países onde estas árvores são cortadas ou danificadas aquando da realização de edificações (e.g. Roménia).

Como critérios de monumentalidade menos significativos usados na classificação das árvores monumentais anotam-se os seguintes: tronco oco, composição do hábito, traços únicos (elementos identitários e específicos da árvore), valor de utilidade, sagradas (atendendo a crenças culturais de determinados países), espécie e estatuto de conservação. Apesar do valor educacional ser transversal a outros critérios de seleção, relevante na promoção da cultura científica, é alvo de referência específica na documentação da Comunidade de Valência (Espanha), Holanda e Rússia.

Há, igualmente, referência à proteção das árvores de elevado valor social, isto é, que foram testemunhas de eventos históricos importantes, ou que se encontrem associadas a mitos e lendas, constituindo elementos de recreio, crenças e tradições populares, fazendo parte da memória e do imaginário coletivo nacionais, ou que estejam associadas a figuras relevantes da cultura local (e.g. Portugal, Estónia, Letónia, Dinamarca). De igual modo, são consideradas as árvores sagradas e de elevado valor cultural para as comunidades (e.g. Turquia, Dinamarca), ou que se encontrem localizadas em lugares sagrados e místicos (Estónia).

$\mathrm{Na}$ maioria dos países selecionados, a legislação é clara ao considerar a proteção de árvores isoladas e conjuntos arbóreos localizados nas mais diversas paisagens (naturais, rurais, urbanas), referindo, por exemplo, o caso de árvores que apresentem elevado valor paisagístico por se encontrarem a embelezar monumentos ou lugares de culto. Esta observação é coerente com estudos anteriores (FrASCAROLI et al. 2016) que referem que um grande número de árvores antigas foi deliberadamente protegido em florestas antigas e perto de locais históricos e religiosos como templos, santuários, igrejas e cemitérios, ou em parques urbanos.

\subsection{Inventários e participação pública}

A proteção e a identificação destas árvores 


\begin{tabular}{|c|c|c|c|c|c|c|c|c|c|c|c|}
\hline & 袌 & 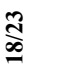 & $\stackrel{-1}{5}$ & $\underset{\tilde{\sigma}}{\tilde{3}}$ & $\frac{\pi}{\pi}$ & & 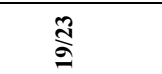 & $\underset{\Phi}{\tilde{\Phi}}$ & $\frac{\pi}{6}$ & $F \pi$ & \\
\hline 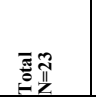 & 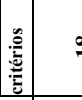 & $\stackrel{\infty}{-}$ & 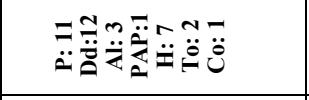 & 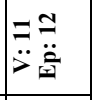 & 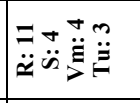 & $\stackrel{\infty}{\ddot{*}}$ & 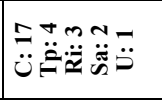 & 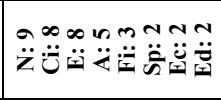 & $\stackrel{n}{\ddot{I}}$ & $\ddot{\sharp}$ & \\
\hline 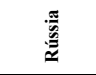 & & - & 芯运远 & 요 & ' & I & 0 & Z四矛 & ' & ' & \\
\hline 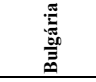 & & - & ব底 & ' & $\Xi$ & ' & ' & 江 & $\leq$ & & \\
\hline 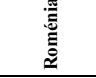 & & - & ' & ' & ' & I & 0 & ' & ' & & \\
\hline 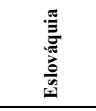 & & - & $\widetilde{\Omega}$ & $>$ 田 & $\overbrace{\approx}^{z}$ & I & 0 & ש & $\unlhd$ & \lrcorner & \\
\hline 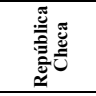 & & - & $a$ & $>$ 正 & $\simeq$ & $I$ & $u$ & 山 & $\unlhd$ & & \\
\hline 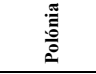 & & - & $\sim \breve{\triangle} \pm$ & 요 & ' & $I$ & 0 & $z:$ & ' & ' & \\
\hline 苞 & & , & & , & , & , & ' & & , & & \\
\hline 営 & & - & "ू & 요 & $\simeq$ & $I$ & $u$ & z品 & $\leq$ & ' & \\
\hline$\frac{\pi}{\overline{\frac{n}{m}}}$ & & ' & & ' & & \pm & 㻤 & ت & $\unlhd$ & & \\
\hline 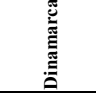 & & - & $=$ & , & $z$ & \pm & $\beta \tilde{n}$ & ' & ' & . & \\
\hline 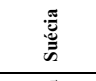 & & \pm & 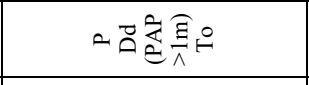 & $>$ & ' & $\Psi$ & u & «山 & $\unlhd$ & د. & \\
\hline 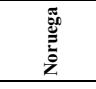 & & $=$ & $\breve{a} \mapsto$ & ' & ' & ' & ' & ' & ' & ' & \\
\hline 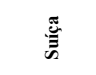 & & - & $\sim \vec{a}$ & $>$ & $\simeq$ & $\Psi$ & 0 & ' & ' & ' & \\
\hline 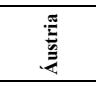 & & ' & & Pि & $\cong \approx$ & ' & 0 & ت & $\unlhd$ & ' & \\
\hline 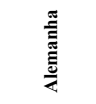 & & ' & & $>$ & $\simeq \backsim$ & I & $0 \ddot{x}$ & $z \dot{U} \varangle \hat{~}$ & $\unlhd$ & , & \\
\hline 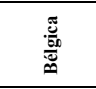 & & - & & ' & & . & & 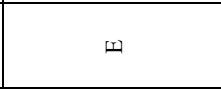 & ' & . & \\
\hline 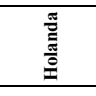 & & 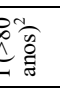 & a) & 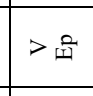 & $\simeq$ & $I$ & 0 & Z句山江司 & 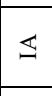 & ' & \\
\hline 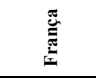 & & - & 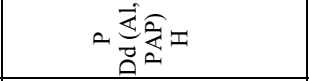 & $>$ & $\simeq$ & \pm & $0 \ddot{\simeq}$ & $z \ll$ & $\unlhd$ & & \\
\hline 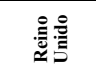 & & ' & $a \pm$ & > & $\Xi$ & \pm & $D$ & $\varpi$ & $\unlhd$ & 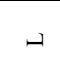 & \\
\hline$\underline{\underline{\underline{z}}}$ & & - & 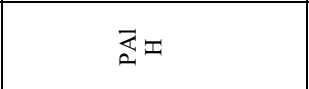 & f뵹 & $\simeq$ & I & 0 & $z: U$ & $\leq$ & . & \\
\hline 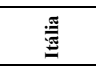 & & - & 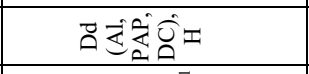 & 요 & $\simeq$ & \pm & 0 Fि: & $\mathrm{Z} \omega \ll$ & $\leq$ & 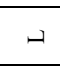 & \\
\hline 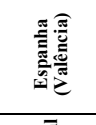 & 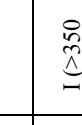 & 至 & 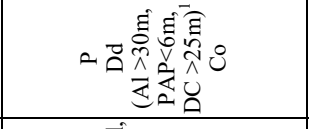 & $>$ 舟 & $n$ & \pm & u & $\tilde{U}<$ के & $\unlhd$ & ' & \\
\hline 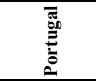 & & - & 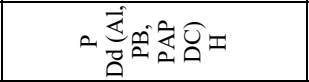 & >苗 & $\simeq \backsim \xi \xi$ & \pm & $0 \approx$ & Z诖㞻 & $\unlhd$ & & \\
\hline 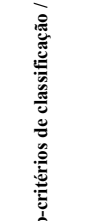 & & 원 & 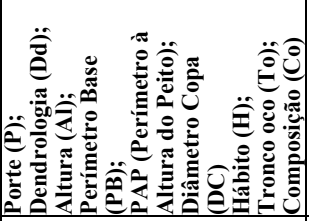 & 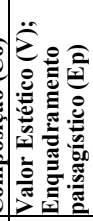 & 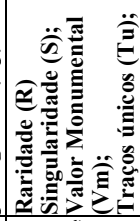 & 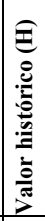 & 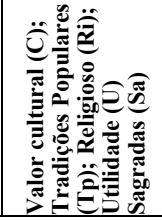 & 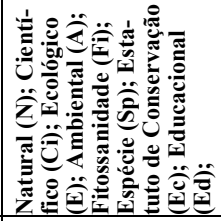 & 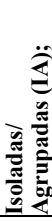 & 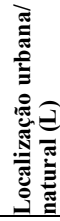 & \\
\hline 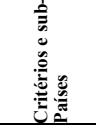 & & 苔 & 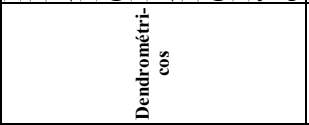 & $\frac{8}{8}$ & 旁 & & 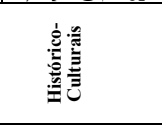 & 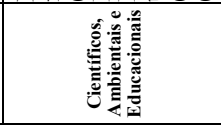 & 要 & 甾 & \\
\hline
\end{tabular}


em inventário constituem uma importante ferramenta para monitorizar este património, atendendo aos vários fatores de condicionalismo a que se encontra sujeito, e que contribuem para o seu desaparecimento. A título de exemplo, em Espanha, durante o século XX foram perdidas $80 \%$ das árvores singulares (TAPIA et al. 2015). Como forma de contrariar estes dados e proteger os exemplares arbóreos monumentais foram objeto de análise a existência de catálogos online, nos vinte e três países analisados. Apenas em dois países não se verificou o inventário das árvores monumentais (Áustria e Croácia). Os restantes países apresentam registos do seu património arbóreo monumental protegido ou não pela legislação, verificando-se que esses inventários se encontram desenvolvidos a nível oficial, quer por instituições do Estado (e.g. Portugal, Suíça, Rússia, Espanha, Itália, Turquia, Noruega, Suécia, Letónia, Estónia, Polónia, República Checa, Eslováquia, Bulgária), quer por Organizações Não Governamentais (ONG's) (e.g. Reino Unido, França, Holanda, Bélgica, Alemanha, Dinamarca, Roménia) (Tabela 4). Estes inventários disponibilizam, para consulta pública, um conjunto de informações (e.g. identificação da árvore, localização, relevância da classificação, dados dendrológicos, data da classificação, últimas medições) passível de utilização para além dos fins conservacionistas, como por exemplo, para a gestão e planeamento do território (e.g. Noruega, Suécia). Estes inventários constituem ainda um acervo de enorme importância, uma vez que há países onde as árvores têm sido monitorizadas, repetidamente, nas últimas décadas (e.g. Reino Unido, República Checa, Letónia, Bélgica). Noutros países, os registos de árvores monumentais têm ainda como fito pressionar os governos a tomar medidas de proteção adequadas para a conservação deste património natural, o que é sobretudo importante naqueles onde a legislação é vaga ou de eficácia reduzida (e.g. França, Holanda, Bélgica, Dinamarca) ou mesmo inexistente (e.g. Roménia). No entanto, apesar do reconhecimento do valor que estas árvores apresentam, o facto de estarem catalogadas em inventário não as protege per si (BENGTSSON 2015).

Em vários países verificou-se que os dados recolhidos em inventário serviram para a publicação de catálogos das árvores monumentais (e.g. Portugal, Suíça, Turquia, República Checa, Rússia), que incluem informação técnica, científica e etnográfica. Mais recentemente, assiste-se à disponibilização destes catálogos online, em websites desenvolvidos para o efeito, na maioria dos países da amostra (e.g. Portugal, Itália, Reino Unido, Alemanha, Bélgica, Suíça, Suécia, Noruega, Turquia).

\section{DISCUSSÃO}

\subsection{Legislação e critérios}

Apesar da diversidade de territórios geográficos e das políticas na matéria de proteção das árvores monumentais, a análise global da legislação aponta para a necessidade em se identificarem e protegerem as árvores com características monumentais, a partir de enquadramentos legais específicos e não específicos, mas diretamente relacionada com a proteção deste património.

Relativamente aos critérios identificados, na legislação, que permitem selecionar as árvores monumentais das demais árvores verifica-se que a longevidade e o valor histórico e cultural associado às árvores monumentais apresentam uma maior frequência nos vários países analisados. Também com relativa expressão surgem os critérios dendrométricos, científicos, ambientais e educacionais e estéticos. Apesar de alguns critérios sobressaírem em relação a outros anota-se a sua heterogeneidade, sendo utilizados tanto critérios científicos (e.g., ambientais, ecológicos, educacionais, dendrométricos) como os que advém da importância que a árvore possa assumir para a comunidade local. Estes resultados são condizentes com os estudos de Jones et al. (2018) que referem a importância de serem usados tanto critérios naturais, como sociais, na proteção de grandes árvores antigas, pois oferecerem uma nova esperança para a perpetuidade de florestas antigas nos ecossistemas e na biodiversidade, cada vez mais rara e que depende delas.

$\mathrm{Na}$ legislação analisada constatou-se uma diversidade de perceções sobre o entendimento territorial de árvore monumental. É sobretudo importante verificar que prevalecem as razões de ordem subjetiva, como a emoção, o respeito e a admiração que uma árvore monumental suscita no observador, assim como o valor intrínseco associado à excecionalidade do exemplar, tal como referem anteriores estudos (CARAMIELLO \& GROSSONI, 2004). Essa autenticidade deve-se, sobretudo, à idade, ao tamanho extraordinário da espécie, ao porte, ao hábito, vitalidade, raridade, apresentando um carácter simbólico ou um valor excecional específico, do ponto de vista histórico-cultural, ecológico, científico, educacional, de reconhecimento popular, estético ou paisagístico tal como é objeto de análise em vários estudos (RIGUEIRo RodRíGUES 2005; PARÉs EsPaÑol 2009; RAMÓN FernáNDEZ 2018). Os resultados são convergentes com os de investigações anteriores que referem que definir uma árvore monumental (antiga, gigante, notável) não é uma questão simples e depende de muitos fatores, como por exemplo, o tipo de floresta, espécie de árvores, condições do habitat, sendo possível encontrar várias propostas na literatura (LiNDENMAYER et al. 2012).

A nível europeu, e apesar do avanço dado pelo registo do património arbóreo, continua a não existir uma política comum para a gestão e conservação destas árvores (BLICHARSKA \& MiKUSIŃSKI 2014), assistindo-se a uma diversidade de designações, definições e critérios de seleção tal como anotado noutras investigações (LISA 2011; CANNIZZARO \& CORINTO 2014).

\subsection{Condicionalismos e restrições}

A maioria dos países com legislação específica e não específica, mas diretamente relacionada 
Tabela 4: Recolha dos catálogos online sobre árvores monumentais nos países da amostra [Collectionof online catalogson monumental trees in

\begin{tabular}{|c|c|c|c|c|c|}
\hline \multirow[b]{2}{*}{ Países } & \multicolumn{4}{|c|}{ Catálogo de Árvores Monumentais online } & \multirow[b]{2}{*}{ Observações } \\
\hline & Existência & Entidade & Âmbito & $\begin{array}{l}\mathbf{N}^{0} \text { árvores } \\
\text { classificadas }\end{array}$ & \\
\hline Portugal & Sim & Estado & Nacional & $\begin{array}{l}470 \text { isoladas e } \\
81 \text { agrupadas }\end{array}$ & $\begin{array}{l}\text { O Registo Nacional do Arvoredo de Interesse Público } \\
\text { (RNAIP) apresenta processos de classificações desde } \\
\text { 1939. URL: } \underline{\text { http://www2.icnf.pt/portal/florestas/aip/ }} \\
\text { arvores-mon-pt-online }\end{array}$ \\
\hline Espanha & Sim & $\begin{array}{l}\text { Comunidades } \\
\text { Autónoma }\end{array}$ & Regional & $\begin{array}{l}\text { Depende da } \\
\text { Comunidade } \\
\text { Autónoma }\end{array}$ & $\begin{array}{l}\text { Comunidade Autónoma deValência.URL: http:// } \\
\text { www.agroambient.gva.es/es/web/medio-natural/catalogo). } \\
\text { As Comunidades de Cantabria, Islas Baleares, La Rioja, } \\
\text { Madrid, Aragón e Castilla-La Mancha com um total de } \\
3.500 \text { árvores, onde mais de } 100 \text { pertencem a espécies } \\
\text { diferentes (Ramón Fernández, 2018; Rigueiro Rodrígues, } \\
\text { 2005b). }\end{array}$ \\
\hline Itália & Sim & Estado & Nacional & 2.739 & $\begin{array}{l}\text { 1982: primeiro censo nacional desenvolvido pelo Corpo } \\
\text { Forestale dello Stato (com } 22.000 \text { árvores, onde mais de } \\
2.000 \text { foram consideradas de alto interesse e } 150 \text { de exce- } \\
\text { cional valor histórico e monumental). } \\
\text { Diário Oficial de } 12 / 02 / 2018 \text { : aprova a nova lei } \\
\text { elaborada de acordo com o artigo } 7^{\circ} \text { da Lei de } 14 \text { de } \\
\text { janeiro de } 2013, \text { n. } 10 \text { (inventário com } 2407 \text { entradas, } \\
\text { posteriormente, atualizado com } 332 \text { novas inscrições das } \\
\text { Regiões de Lácio, Lombardia, Molise e Sardenha). } \\
\text { URL:https://www.politicheagricole.it/flex/cm/pages/ } \\
\text { ServeBLOB.php/L/IT/IDPagina/11266 }\end{array}$ \\
\hline Turquia & Sim & Município & Regional & $\begin{array}{l}\text { Lado europeu: } \\
2.524 \\
\text { Lado da Anató- } \\
\text { lia: } 2.593\end{array}$ & $\begin{array}{l}\text { Registo das "árvores monumento" do lado europeu e do } \\
\text { lado da Anatólia. URL: https://www.anitagaclar.com/ }\end{array}$ \\
\hline $\begin{array}{l}\text { Reino } \\
\text { Unido }\end{array}$ & Sim & $\begin{array}{l}\text { Organizações } \\
\text { Não } \\
\text { Governamentais }\end{array}$ & Nacional & 170.000 & $\begin{array}{l}\text { O registo nacional, The Ancient Tree Inventory (ATI) foi } \\
\text { desenvolvido em parceria com a Woodland Trust (WT), } \\
\text { Tree Register of the British Isles e Ancient Tree Forum } \\
\text { (ATF) (Haw 2014; Lonsdale 2013; WOODLAND TRUST } \\
\text { 2008). }\end{array}$ \\
\hline França & Sim & $\begin{array}{l}\text { Organizações } \\
\text { Não } \\
\text { Governamentais }\end{array}$ & Nacional & 500 & $\begin{array}{l}\text { 1996: o Office Nationaldes Forêts (ONF) recenseou } 2.048 \\
\text { árvores de interesse local, municipal, regional e nacional. } \\
\text { Office National des Forêts. URL:http://www.onf.fr/ } \\
\text { gestion_durable/sommaire/coeur_societe/espace imagine/ } \\
\text { elements_remarquables/@@index.html } \\
\text { 2012-presente: a ONF colabora com a Association } \\
\text { A.R.B.R.E.S.,Arbres remarquables de France, na elabora- } \\
\text { ção do mapa interativo das árvores notáveis de França. } \\
\text { URL: https://www.arbres.org/ } \\
\text { arbres_remarquables.html\#ancre01 }\end{array}$ \\
\hline Holanda & Sim & $\begin{array}{l}\text { Organizações } \\
\text { Não } \\
\text { Governamentais }\end{array}$ & Nacional & 5.000 isoladas & $\begin{array}{l}2015 \text { - presente: Registo Nacional de Arvores Monumen- } \\
\text { tal (Landelijk Register van Monumentale Bomen) da } \\
\text { "Fundação Árvore" (Bomenstichting). URL:https:// } \\
\text { bomen.meetnetportaal.nl/source/index.php? } \\
\text { c=portal\&mm=claim\&m=custom\&options=monumentale } \\
\text { bomen/claimformulier.xml }\end{array}$ \\
\hline Bélgica & Sim & $\begin{array}{l}\text { Organizações } \\
\text { Não } \\
\text { Governamentais }\end{array}$ & Nacional & $>27.000$ & $\begin{array}{l}1984 \text { - presente: a Sociedade Belga de Dendrologia tem } \\
\text { desenvolvido a BELTREES DATABASE com árvores } \\
\text { monumentais de todo o território, algumas das que cons- } \\
\text { tam no inventário têm sido, repetidamente, medidas nos } \\
\text { últimos trinta anos. URL: } \text { http://www.belgiumview.com/ } \\
\text { tl1main/lijstmap.php?blad=soort\&naamlike }=000147 \\
\text { https://www.arboretumwespelaar.be/Default.aspx? } \\
\text { Menu=MenuTop\&MIID=383\&WPID=291\&L=E }\end{array}$ \\
\hline Alemanha & Sim & $\begin{array}{l}\text { Organizações } \\
\text { Não } \\
\text { Governamentais }\end{array}$ & Nacional & 7.385 & $\begin{array}{l}2009 \text { - presente: a Sociedade Alemã de Dendrologia } \\
\text { (DDG) e a Sociedade de Arboricultura Alemã (GDA) tem } \\
\text { desenvolvido o Catálogo: “Árvores Recordistas e Cam- } \\
\text { peãs da Alemanha”. URL: https://www.ddg-web.de/ } \\
\text { index.php/rekordbaeume.html }\end{array}$ \\
\hline Suíça & Sim & Cantão & $\begin{array}{l}\text { Nacional } \\
\text { e } \\
\text { Regional }\end{array}$ & 190 & $\begin{array}{l}\text { 1900: Album de árvores da Suíça (Baum-Album der } \\
\text { Schweiz), publicado pelo Departamento Florestal da Suíça, } \\
\text { descreve } 23 \text { árvores notáveis individuais (URL: https://szf- } \\
\text { jfs.org/doi/abs/10.3188/szf.1999.0187). } \\
\text { Atualmente existe um mapa interativo com árvores monu- } \\
\text { mentais protegidas (URL: https://ge.ch/tericasaisie/); } \\
\text { qualquer cidadão pode identificar e propor para avaliação } \\
\text { uma árvore com características monumentais (Denzler, } \\
\text { 1999; Perroulaz, 2015). }\end{array}$ \\
\hline
\end{tabular}




\begin{tabular}{|c|c|c|c|c|c|}
\hline Noruega & Sim & Governo & Nacional & $\begin{array}{l}2.768 \text { áreas com } \\
\text { carvalhos ocos }\end{array}$ & $\begin{array}{l}\text { 2013: a Naturbase identificou áreas com carvalhos ocos. } \\
\text { URL: } \text { https://www.miljodirektoratet.no/verktoy/naturbase/ }\end{array}$ \\
\hline Suécia & Sim & $\begin{array}{l}\text { Administrações } \\
\text { distritais }\end{array}$ & Nacional & 580.000 & $\begin{array}{l}\text { O "Portal da Árvore" (Träd portalen) constitui um catálo- } \\
\text { go online com árvores com características monumentais, } \\
\text { onde } 441.256 \text { apresentam especial proteção } \\
\text { (NATURVARDSVERKET RAPPORT, 2012). Träd } \\
\text { portalen. URL: https://www.tradportalen.se/ }\end{array}$ \\
\hline Dinamarca & Sim & $\begin{array}{l}\text { Organizações } \\
\text { Não } \\
\text { Governamentais }\end{array}$ & Nacional & 877 & $\begin{array}{l}\text { 1950: a Danish Dendrological Society tem catalogado as } \\
\text { árvores monumentais. URL: } \text { http://www.dendron.dk/dtr/ } \\
\text { soeg/default.asp; Christensen 2009). }\end{array}$ \\
\hline Estónia & Sim & Governo & Nacional & 735 & $\begin{array}{l}\text { 2003: o Conselho Ambiental da Estónia protege árvores } \\
\text { (Puu) monumentais através do "Regulamento para a prote- } \\
\text { ção de objetos naturais" (Kaitstavate looduse üksikobjekti- } \\
\text { de kaitse-eeskiri). URL: https://www.riigiteataja.ee/ } \\
\text { akt/13132781?leiaKehtiv. Os "Planos de Desenvolvimen- } \\
\text { to" (Arengukava 2008-2012, 2015-2020) têm permitido } \\
\text { inventariar os "Santuários Naturais" (Looduslikud püha- } \\
\text { paigad). URL: http://maatundmine.estinst.ee/kohad// } \\
\text { annemagi/41-annemagi/; }\end{array}$ \\
\hline Letónia & Sim & Governo & Nacional & 5.098 & $\begin{array}{l}1920 \text { - presente: são recolhidos dados sobre árvores gigan- } \\
\text { tes (dižkokus). Em 1977, encontravam-se inventariadas } \\
817 \text { árvores gigantes e protegidas por lei, enquanto monu- } \\
\text { mentos naturais, e em 1986, } 1.530 \text { árvores. Em 2018, no } \\
\text { "Inventário Histórico e Cultural da Letónia" (não oficial) } \\
\text { estavam identificadas } 5.098 \text { exemplares, das quais } 2.748 \\
\text { eram de significância nacional e } 275 \text { protegidas como } \\
\text { monumentos naturais. URL: https://dziedava.lv/daba/ } \\
\text { koku db.php. Nos últimos anos, o "Fundo do Património } \\
\text { da Natureza da Letónia" disponibilizou um catálogo onli- } \\
\text { ne com as árvores recordistas com vista à sua exploração. } \\
\text { URL: http://www.dabasretumi.lv/Pieminekli/Ekoki.htm }\end{array}$ \\
\hline Polónia & Sim & Governo & Nacional & 3.175 & $\begin{array}{l}\text { O registo nacional de monumentos naturais (Centralny } \\
\text { rejestr form ochrony przyrody). URL: http:// } \\
\text { crfop.gdos.gov.pl/CRFOP/index.jsf }\end{array}$ \\
\hline $\begin{array}{l}\text { República } \\
\text { Checa }\end{array}$ & Sim & Governo & Nacional & 25.598 & $\begin{array}{l}\text { 1899: primeiro livro sobre árvores monumento. } \\
\text { Final da } 2^{\mathrm{a}} \text { Guerra Mundial - 1956: o desenvolvimento do } \\
\text { inquérito nacional, Survey of Memorable or Remarkable- } \\
\text { Trees, Tree Avenues and Forests, pelo State Institute of } \\
\text { Cultural Heritage and Nature Conservation, conduzido } \\
\text { por voluntários permitiu verificar que a maioria das árvo- } \\
\text { res protegidas foi perdida. } \\
1992 \text { - presente: a Agência para Conservação da Natureza } \\
\text { tem desenvolvido um catálogo nacional, queem } 2017 \\
\text { apresentava } 25.598 \text { árvores monumentais, onde } 80 \% \text { são } \\
\text { árvores isoladas e 20\% grupadas (ÚRADNíčEK et al. 2017). } \\
\text { URL: https://drusop.nature.cz/ost/chrobjekty/pstromy/ } \\
\text { index.php? }\end{array}$ \\
\hline Eslováquia & Sim & Governo & Nacional & 443 & $\begin{array}{l}\text { 2002: criação do catálogo nacional. URL:https:// } \\
\text { www.enviroportal.sk/stromy }\end{array}$ \\
\hline Roménia & Sim & $\begin{array}{l}\text { Organizações } \\
\text { Não } \\
\text { Governamentais }\end{array}$ & Nacional & 4.586 & $\begin{array}{l}\text { Projeto Remarkable Trees of Romania. URL: https:// } \\
\text { arboriremarcabili.ro/en/about-project/ }\end{array}$ \\
\hline Bulgária & Sim & Governo & Nacional & 1.465 & $\begin{array}{l}\text { Registo nacional. URL: http://eea.government.bg/v-trees/ } \\
\text { bg/index.jsp }\end{array}$ \\
\hline Rússia & Sim & Governo & Nacional & 509 & $\begin{array}{l}\text { "Registo Nacional de Árvores Antigas da Rússia". } \\
\text { URL:http://treeportal.ru/index.php? } \\
\text { opti- } \\
\text { on=com_adsmanager\&page=show category\&catid=1\&or } \\
\text { der }=0 \text { \&expand=0\&Itemid=85. }\end{array}$ \\
\hline
\end{tabular}

com a proteção das árvores monumentais, apresenta detalhes sobre os procedimentos a atender para a proteção deste património. Existe a preocupação em detalhar os condicionalismos a que a árvore fica sujeita quando se torna protegida, prevendo a legislação uma zona geral de proteção ao redor das árvores (e.g. Portugal, $50 \mathrm{~m}$; Noruega, $15 \mathrm{~m}$; Estónia, $50 \mathrm{~m}$; Letónia, $10 \mathrm{~m}$; República Checa, corresponde a um círculo com um raio igual a dez vezes o perímetro do tronco medido à altura do peito da árvore - 1,30 m - ; Eslováquia, corresponde à pro- jeção da copa prolongada desde um 1,5 m a um raio mínimo de 10 metros). Nesta zona tampão, são impostas restrições às intervenções que possam cortar, danificar, total ou parcialmente, este património natural. Qualquer ação (e.g. corte, transplante, obras de construção, alterações no terreno, drenagem, tratamento químico) que prejudique a árvore é, ainda, proibida (e.g. Portugal, Espanha, Itália, Turquia, Alemanha, Suécia, Estónia, Bulgária), atendendo ao seu "Benefício Público Superior" (Turquia) ou quando qualquer intervenção ca- 
rece de autorização (e.g. Portugal). São igualmente referidos os valores das coimas a aplicar no caso de contraordenações (e.g. Portugal, Reino Unido). Na legislação, há a referência à colocação de sinalética identificativa das árvores protegidas (e.g. Portugal, Alemanha). Estes resultados sublinham a importância dada a este património, reconhecendo ainda que o mesmo deve ser protegido e salvaguardado em virtude da pressão natural e humana, tal como tem sido reportado em vários estudos científicos (HAw 2014; LiNDENMAYER et al. 2013; LINDENMAYER \& LAURANCE 2017; PATRUT et al. 2018; LiU et al. 2019).

Também os catálogos online analisados permitiram verificar a importância que este património assume nos diferentes países da amostra. Para além de referenciarem árvores de excecional valor, estes inventários sistemáticos permitem, entre outros, recolher parâmetros dendrométricos ao longo de várias décadas, registos históricos e culturais a elas associadas, ou determinar as medidas de manutenção e proteção necessárias para a sua sobrevivência.

No desenvolvimento do estudo foram várias as dificuldades com as quais a equipa de investigadores se deparou, sobretudo relacionadas com a seleção das fontes de informação, em virtude do elevado número de países da amostra. Também a barreira linguística constituiu um entrave, ao desenvolvimento do estudo, especialmente devido ao não domínio da língua, dos vários países alvo de análise, como a Estónia, Dinamarca, Letónia, Croácia ou Rússia. Para contornar esta situação os investigadores recorreram à tradução dos documentos para a língua portuguesa. A morosidade ou a ausência de resposta por parte dos contactos internacionais estabelecidos, com outros investigadores que trabalham na área da proteção e divulgação das árvores monumentais, contribuíram, igualmente, para dificultar o processo de recolha e análise dos dados.

\section{CONCLUSÃO}

A investigação foi conduzida no sentido de colmatar a ausência de estudos relativos à comparação internacional da legislação, na matéria de proteção das árvores monumentais. A pertinência do estudo é, igualmente, reforçada no atual enquadramento das alterações climáticas, pelo facto das árvores monumentais, particularmente, as antigas e de elevado porte contribuírem significativamente para a sua mitigação, como comprovam vários estudos, nesta matéria. Também o nível de abrangência constitui um fator positivo, atendendo ao elevado número de países da amostra.

Não questionando a legislação produzida pelos diferentes países da amostra, facilmente constatamos que, apesar da heterogeneidade de enquadramentos legais, existe, no geral, um reconhecimento do valor que as árvores monumentais apresentam e da necessidade em as identificar e proteger. Quanto aos critérios de seleção usados para reconhecer a importância destas árvores, apesar de diversos, abarcando funções ecológicas ou a ímpar herança que estas árvores representam para a comunidade, verifica-se que o especial foco é dado à longevidade das árvores e ao seu valor histórico e cultural. Apesar da diferença verificada entre os diferentes países é positivo constatar que a maioria da amostra apresenta um enquadramento legal traduzido, especialmente por Decretos-Lei e Regulamentos, de abrangência nacional, o que reflete a preocupação conferida às árvores monumentais e ao especial interesse na sua proteção.

Existem quadros jurídicos que podem servir de exemplo, na matéria da proteção das árvores, por apresentarem critérios claros, tanto na seleção das árvores monumentais como na aplicação de medidas efetivas da sua proteção (e.g. Portugal, Itália), comparativamente a outros países onde a legislação existente deve ser aperfeiçoada (e.g. França) ou, ainda, onde se verifica um vazio legislativo nesta matéria (e.g. Croácia, Roménia). Esta questão é importante para que não se assista à perda de biodiversidade e de património natural e histórico-cultural valioso.

Relativamente aos inventários verificouse a importância que assumem, na grande maioria dos países da amostra sendo, em muitas situações, anteriores à legislação em vigor, e realizados durante várias décadas o que tem permitido monitorizar os exemplares referenciados em épocas passadas.

Em contexto nacional, face à problemática da perda de biodiversidade e das alterações climáticas com a necessidade de encetar medidas de proteção, conservação ambiental e patrimonial, a legislação específica, na matéria da proteção das árvores monumentais verificada, afigura-se como bastante completa na salvaguarda do arvoredo monumental classificado ou com potencial de classificação, o que constitui um marco legislativo muito pertinente, atendendo à sua abrangência nacional, logo após a sua instituição, em 1914. Destacam-se ainda, países como Espanha (Comunidade de Valência) e Itália, pela semelhança de grau de especificidade da legislação com o nosso país.

Apesar das dificuldades no desenvolvimento do estudo, as mesmas foram contornadas, constituindo, globalmente, os resultados obtidos, um importante contributo para o conhecimento da legislação em vigor, na matéria da proteção das árvores monumentais, num amplo conjunto de países do continente europeu.

Os resultados desta investigação justificam a importância de se criar uma lei comum para a uniformização da inventariação, proteção e implementação de medidas restritivas e sancionatórias, que confira proteção legal às árvores monumentais do espaço comunitário. Futuramente, os resultados obtidos podem guiar investigações mais detalhadas, permitindo promover a reflexão sobre a temática e servir até de referência, atendendo aos atuais desafios que este património natural enfrenta. Igualmente, estes resultados, podem vir a apoiar futuras orientações das escolhas públicas, na aferição de um modelo legislativo comum e de referência europeia para uma abordagem mais consistente e cooperativa, na preservação das árvores monumentais enquanto entidades biológicas e culturais de inestimável valor. 
Comitantemente, os resultados podem promover melhores resultados de conservação e informação junto do público especialista e não-especialista para se contribuir para uma efetiva proteção deste património. Tal, pode ser assegurado não apenas pela uniformização da legislação, como pela mobilização da sociedade em geral, pelo desenvolvimento de estratégias public engagement, prática esta já existente, possibilitando que a identificação dos exemplares e sua proteção não esteja só a cargo das autoridades competentes, mas também da sociedade em geral, especializada e não especializada. Estas ações podem limitar as atuais perdas de árvores grandes e velhas e contribuir para renovar este património nas próximas gerações.

\section{AGRADECIMENTOS}

Raquel Pires Lopes é financeiramente suportada com uma bolsa de investigação atribuída pela Fundação para a Ciência e a Tecnologia (FCT), SFRH/BD/91905/2012.Os autores gostariam de agradecer a colaboração prestada por diversas pessoas que foram essenciais para o desenvolvimento deste estudo: Marcolino Fritz Vilaça (Arboricultor, Portugal); Amália Souto de Miranda (Loci studio Arquitetura paisagista, Portugal); Owen Johnson (The Tree Register, Reino Unido); Lionel Staub (Association A.R.B.R.E.S., Protection et Labellisation des Arbres Remarquables de France, França); Maaike Brasz (SBNL Natuurfonds, Holanda); Robert Perroulaz (USSP - Union Suisse des Services des Parcs et Promenades, Suíça); Glen Read (Tree Solution, Noruega); Vikki Bengtsson (Pro Natura, Suécia); Dani Mladoniczky (Svenska Trädföreningen, Suécia); Christian Nørgård Nielsen (SkovByKon, Dinamarca); Maria Smirnova (Muinsuskaitseamet - National Heritage Board of Estonia, Estónia); Ivana Konjevod (Stručnisuradnik, Croácia); Jola Migdał (Klub Gaja, Polónia); Andrea Krůpová (Tree of the Year; Nadace Partnerství I Environmental Partnership Association, Républica Checa); Libor Sedláček (Nature Conservation Agency of the Czech Republic, Républica Checa) Gabriela Manea (GEO - CARTEDD, Roménia), Viorel Arghius (Faculty of Environmental Science Department of Life and Earth Sciences, Babes-Bolyai University, Roménia), Tibor Hartel (Hungarian Department of Biology and Ecology, Babes-Bolyai University, Roménia), Tamás Réka (Pogány-havas Association, Roménia); and Lubomira Kolcheva (Bulgarian Environmental Partnership Foundation, Bulgária).

\section{BIBLIOGRAFIA}

American Forest. 2019. Big Trees, American Forests Protecting and Restoring Forests, disponível em $<$ https://www.americanforests.org/get-involved/ americas-biggest-trees/>, consultado em janeiro de 2019

A.R.B.R.E.S (Arbres Remarquables: Bilan, Recherche, Études et Sauvegarde). 2019. Association A.R.B.R.E.S, disponível em $<$ https://www.arbres.org/l-association-a-r-b-r-e-s.htm >, consultado em janeiro de 2019.

Bengtsson, V. 2015. Värna skyddsvärda träd [Vale a pena proteger árvores]. Skydd av värdefulla träd Vägledning för naturvărdsanvariga på kommuner [Proteção de árvores valiosas - orientação para agentes de conservação da natureza dos municípios].LONA-medel.

BlicharSKA, M. \& MiKusIŃSKI, G. 2014. Incorporating Social and Cultural Significance of Large Old Trees in Conservation Policy. Conservation Biology, 28 1558-1567.

Cannizzaro, S. \& Corinto, G.L. 2014. The role of monu- mental trees in defining local identity and in tourism: a case study in the Marches Region. Geoprogress Journal (s Humanities 1) 1(1):29-48.

Caramiello, R. \& Grossoni, P. 2004. Monumental trees in historical parks and gardens and monumentality significance. In: G. NicolotTI \& P. GonthiER (Eds.), The trees of history: protection and exploitation of veteran trees. Proceedings of the International Congress, 1-2 Apr 2004. University of Turin, Italy: 3-10 Disponível em<http:// www.cathedralgrove.eu/media/03-2-treeshistory.pdf $>$, junho de 2018.

Carpaneto, G.M.; Mazziotta, A.; Coletti, G.; Luiselli, L. \& Audisio, P. 2010. Conflict between insect conservation and public safety: the case study of a saproxylic beetle (Osmoderma eremita) in urban parks. J. Insect Conserv., 14: 555-565.

Chambers, J.Q.; Higuchi, N. \& Schimel, J.P. 1998. Ancient trees in Amazonia. Nature, 391: 135-136. https:// doi.org/10.1038/34325.

Christensen K. 2009. Dansk Træregister [Danish tree register] Botanisk Have og Museum, Statens Naturhistoriske Museum, Københavns Universitet.

CITES, 1973. Convention on International Trade in Endangered Species of Wild Fauna and Flora. Disponível em $\quad<$ https://www.cites.org/eng/disc/text.php>, consultado em setembro de 2018 .

Corney P. \& Butler J. 2007. Biodiversity Action Plan (BAP) for ancient veteran trees. The Caravan Club. Just Ecology.

DAFNI, A. 2006. On the typology and the worship status of sacred trees with a special reference to the Middle East. J Ethnobiol Ethnomed, 2:26-40.

Decreto n. ${ }^{\circ} 28468$, de 15 de fevereiro de 1938 Árvore de Interesse Público. Disponível em <http://dre.pt/ pdfgratis/1938/02/03700.pdf $>$, junho de 2014 .

Denzler, L. 1999. Das Baum-Album der Schweiz von Johann Coaz - Eine Bestandesaufnahme nach 100 Jahren [«The Swiss Tree Album» by Johann Coaz a Retrospect of the Inventory after 100 Years] Schweiz. Z. Forstwes, 150(5): 187-192.

Diraison, A. 2003. Les Droits de L'Arbre Aide-Mémoire des Textes Juridiques. Ministère de l'Écologie et du Développement Durable. Disponível em $<\mathrm{http}$ :// nature.jardin.free.fr/Droits_arbre.pdf $>$, maio de 2019.

Diretiva 92/43/CEE do Conselho de 21 de maio de 1992 relativa à preservação dos habitats naturais e da fauna e da flora selvagens. Disponível em $<\mathrm{https} / /$ eur-lex.europa.eu/legal-content/PT/TXT/PDF/? uri=CELEX:31992L0043\&from=PT>, consultado em setembro de 2018.

Domínguez Lerena S.; Corchero de la Torre, S. \& Albano Villar, R. 2010. Manual de Buenas Prácticas para los Arboles Singulares. Ministerio de Medio Ambiente, Medio Rural y Marino. Bosques Sin Fronteras.

EU (1992) Council Directive 92/43/EEC. The Conservation of Natural Habitats and of Wild Fauna and Flora. Brussels: EU.

FAO \& Plan Bleu. 2018. State of Mediterranean Forests 2018. Food and Agriculture Organization of theUnited Nations, Rome and Plan Bleu, Marseille.

FAY, N. 2004. Survey methods \& development of innovative arboricultural techniques in key UK veteran tree sites. In: G. NicolotTI \& P. GonthiER (Eds.), The trees of history: protection and exploitation of 
veteran trees. Proceedings of the International Congress, 1-2 Apr 2004. University of Turin, Italy. Disponível em <http://www.arborecology.co.uk/ resources/Reduced_SurveyMethods $\%$

20_Arboricultural_Technique_TURIN_280a.pdf $>$, maio de 2019.

Frascaroli, F.; Bhagwat, S.; Guarino, R.; Chiarucci, A. \& Schmid, B. 2016. Shrines in Central Italy conserve plant diversity and large trees. Ambio 45, 468 -479 .

Golabek, E. \& Tukiendorf, A. 2002. Growth in thickness of monumental English Oaks Quercus robur, and their age, health status and dust fall in Bayesian approach. Polish Journal of Environmental Studies, 11:331-337.

Government Printing Bureau. 2013. Boletim Oficial- I Série: Capítulo X Artigo 106 (Offical Gazette Series I: Chapter X Article 106). Retrieved January 17, 2019, from Government Printing Bureau, Macau SAR Government (September 2). Disponível em <http://bo.io.gov.mo/bo/i/2013/36/lei11.asp>, maio de 2019.

Haw K (editor) 2014. Ancient Trees. Woodland Trust Wood Wise, Woodland Conservation News, 2-15.

Hartel, T.; Hanspach, J.; Moga, C.I.; Holban, L.; Szapanyos, A.; TAMás, R.; Hováth, C. \& Réti, K.O. 2018. Abundance of large old trees in woodpastures of Transylvania (Romania). Science of The Total Environment, 613-614, 263-270.

Imelsa - Diputació de Valência. 2014. Ordenanza Municipal de Protección de Arbolado Monumental de Interés Local. Disponível em <http:/www.imelsa.es/ es_ES/arboles-monumentales/presentacion>, maio de 2018 .

Jones, G.M.; Keane, J.J.; Gutierrez, R.J. \& Peery, M.Z. 2018. Declining old-forest species as a legacy of large trees lost. Divers Distrib, 24(3):341-351.

JIM, C.Y. 2005. Floristics, performance and prognosis of historical trees in the urban forest of Guangzhou City (China). Environmental Monitoring \& Assessment 103: 285-308.

JiM, C.Y. 2017. Urban Heritage Trees: Natural-cultural Significance Informing Management and Conservation. In P.Y. Tan \& C.Y. Jim (Eds.), Greening Cities: Forms and Functions, Singapore, Springer Nature: 279-305. Doi: 10.1007/978-981-10-4113613.

JiM, C.Y. \& LIU, H.T. 2000. Statutory measures for the protection and enhancement of the urban forest in Guangzhou City, China. Forestry 73, 311-329.

Kozlowski, G.; Gibbs, D.; Huan, F.; Frey, D. \& GratzFeld, J. 2012. Conservation of threatened relict trees through living ex situ collections: lessons from the global survey of the genus Zelkova (Ulmaceae). Biodiv Conserv, 21:671685 .

Krebs, P., Conedera, M. \& Fonti, P. 2005. The Inventory of the Giant Chestnut Trees in Southern Switzerland. Chestnut Congress. Acta Horticulturae (ISHS) 693 171-178. Disponível em <http://www.actahort.org/ members/showpdf?booknrarnr $=693 \quad 20>$, maio de 2019

Le Roux, D.S.; Ikin, K.; Lindenmayer, D.B.; Manning, A.D. \& GibBons, P. 2014. The Future of Large Old Trees in Urban Landscapes. PLoS ONE, 9(6): e99403.

Lindenmayer, D.B. 2017. Conserving large old trees as small natural features. Biological Conserva- tion, 211, 51-59.

Lindenmayer, D.B.; Laurance, W.F. \& FranKLin, J.F. 2012. Global decline in large old trees. Science, 338:1305-1306.

Lindenmayer, D.B. \& Laurance, W. 2017. The ecology, distribution, conservation and management of large old trees. Biological reviews of the Cambridge Pilosophical Scociety, 92 (3): 1434-1458.

Lindenmayer, D.B.; Laurance, W.F.; Franklin, J.F.; Likens, G.E.; Banks, S. C.; ... Blanchard, W.\&SteIn, J.A.R. 2013. New policies for old trees: Averting a global crisis in a keystone ecological structure. Conservation Letters, 7: 61-69.

LISA, C. 2011. Gli alberi monumentali: normative, conoscenza e tutela. L'Italia Forestale e Montana, 66 (6): 509-519.

LiU, J.; LindenMayer, D.B.; YANG, W.; Ren, Y.; CAMPBell, M.J.; Wu, C.; Luo, Y.; ZHONG, L. \& Yu, M. 2019. Diversity and density patterns of large old trees in China. Science of The Total Environment, 655: 255262.

LonsDale, D. 2013. Ancient and other veteran trees: further guidance on management. Ancient Tree Forum \& Woodland Trust. London, The Tree Council.

Lopes, R.P.; Schreck ReIS, C. \& TRINCÃO, P.R. 2019. Portugal's trees of public interest: their role in botany awareness. Finisterra, LIV (110): 19-36. Doi: 10.18055/Finis14564.

ManNing, A.D., Fischer, J. \&Lindenmayer, D.B. 2006. Scattered trees are keystone structures implications for conservation. Biol. Conserv., 132 311-321.

Martins, L. \& Travassos, P. 2012. Fitossanidade e segurança das árvores da Escola Francesa - Porto. Vila Real. Universidade de Trás-os-Montes, Departamento de Ciências Florestais e Arquitetura Paisagista.

McIntyre, P.J.; Thorne, J.H.; Dolanc, C.R.; Flint, L.E.; Kelly, M. \& ACKerly, D.D. 2015. ProcNatlAcadSci US A, 112(5):1458-63.

Molina. R., Tudela, S., \& Guillén, S. 2014. Potenciacióndel património natural, cultural y paisagístico com el diseño de itinerários turísticos, en: Cuadernos de Turismo ( $\mathrm{N}^{\mathrm{o}}$ 34, julio-diciembre), pp. 189-201.

Monumentos Nacionais da Natureza, 2019. Disponíve em $\quad<<$ https://www.bmu.de/themen/naturbiologische-vielfalt-arten/naturschutz-biologischevielfalt/gebietsschutz-und-vernetzung/nationalenaturlandschaften/nationale-naturmonumente/ $>$, maio de 2019.

MoyA, B., 2015a. Horizonte 2020, la estratégia para la conservación de la Biodiversidade en la Unión Europea: Retos y oportunidades para los árbolesmonumentales y bosques maduros. Apresentação oral no Congreso Internacional en Arbolar: Grandes árboles para la Vida (BIGTREE4LIFE) - El valor de los árboles y bosques maduros en la salvaguardia de la biodiversidad. Valência, 24 e 25 de março de 2015.

Moya, J., 2015b. 20 años de investigación, protección, conservación y divulgación: El Departamento de Arboles Monumentales. Apresentação oral no Congreso Internacional en Arbolar: Grandes árboles para la Vida (BIGTREE4LIFE) -El valor de los árboles y bosques maduros en la salvaguardia de la biodiversidad. Valência, 24 e 25 de março de 2015.

Moya, B. \& Moya, J. 2012. La Protección Jurídrica de los Tejos Históricos y otros Árboles Monumentales. 
Jornadas sobre Gestión y Conservación de Tejos y otros Arboles Históricos. Jardim Botânico Atlântico 1 e 2 de março. Disponível em <http:/ botanico.gijon.es/multimedia_objects/download? object_id=136550\&object_type=document $>, \quad$ dezembro de 2018 .

Moya, B. \& Moya, J. 2013. Monumental trees and mature forests. Threatened in the Mediterranean Landscapes. València: Imelsa.

NATURVÅRDSVERKET RAPPORT [Relatório de Protecção Natural]. 2012. Åtgärdsprogram för särskilt skyddsvärda träd - mål och åtgärder 2012-2016 [Programa de ação para árvores especialmente protegidas - Metas e medidas de 2012 a 2016]. Disponível em <https:/ www.naturvardsverket.se/Documents/ publikationer6400/978-91-620-6496-9.pdf>, janeiro 2019.

ONF. 2019. Office National des Forêts. Disponível em $<$ http://www.onf.fr/gestion_durable/sommaire/ coeur societe/espace imagine/

elements_remarquables/@@index.html>,janeiro de 2019.

OrLowski, G. \& NowaK, L. 2007. The importance of marginal habitats for the conservation of old trees in agricultural landscapes. Landscape \& Urban Planning79: 77-83.

Pardal, L. \& Correia, E. 1995. Métodos e Técnicas de Investigação Social. Porto Formação Contínua. Areal Editores.

PARÉs EsPañol, E. 2009. Árboles monumentales de Cataluña, 21 años de protección. Actuaciones más frecuentes. In: L.S. Laliga (Editor), III Jornadas Estatales Sobre Árboles Monumentales y Singulares, Situaciónactual de la conservación de nuestros Árboles, Alcoi, Disponível em <http:// www20.gencat.cat/docs/parcsnaturals/Home/ Coneixos/Arbres_monumentals/Per\%20saber_ne\% 20mes/Jornades\%20d'arbres\%20monumentals/ AMAlcoi2008-09 esmodif lam vol.1.pdf $>$, dezembro de 2018.

Patrut, A., Woodborne, S., Patrut, R.T., Rakosy, L., Lowy, D.A., Hall, G. \& Von Reden, K.F. 2018 The demise of the largest and oldest African baobabs. Nat. Plants, 4, 423.

Perroulaz, R. 2015. Actualisation du document de travail La procédure pour évaluer la taille des arbres "remarquables» et "majeurs» du canton et textes relatifs aux arbres historiques de Genève. Arbres à feuilles. Hepia - Haute école du paysage, d'ingénierieet d'architecture de Genève.

RAMÓN FERNÁNDEZ, F. 2018. La protección del patrimonio arbóreo monumental en la legislación española. Sua plicación al turismo y al paisaje. Iuset Praxis, 24 3:109-132.

RigueIRo Rodrígues A. 2005. Árboles singulares: una propuesta de conservación. Instituto de Biodiversidade Agrária e Desenvolvimento Rural (IBADER). Universidade de Santiago de Compostela. Recursos Rurais - Novas Tendencias na Caracterización e Xestión da Biodiversidade. Serie Cursos 2: 73-80. Disponível em <http://www.ibader.org/archivos/ docs/RRM-05-02-07.pdf>, dezembro de 2018

SÁNChez, M. \& ORTEGA, R. 2016. El monocultivo olivarero jiennense: conformación histórica, valores patrimoniales y proyección cultural-turística. Cuadernos de Turismo, 37: 377-402.

Schlawin, J. \& Zahawi, R.A. 2008. 'Nucleating' succession in recovering neotropical wet forests: the legacy of remnant trees. $J$ VegSci, 19:485-492.
SCHLUMPrecht, H. \& KaISER, T. 2015. Nationale Naturmonumente: naturschutzfachliche Fragen und Denkanstöße zu einer neuen Schutzgebietskategorie und $\mathrm{zu}$ deren Operationalisierung [Monumentos Naturais Nacionais: questões de conservação da natureza e de reflexão para uma nova categoria de áreas protegidas e sua operacionalização]. Natur $u$. Landschaft $90,15-28$.

Stagoll, K., Lindenmayer, D.B., Knight, E., Fischer, J. \& ManNing, A.D. 2012. Large trees are keystone structures in urban parks. Conserv Lett, 5:115-122.

Stephenson, N.L.; Das, A.J., Condit, R.; Russo, S.E.; BAKER, P.J.; BECKMAN, N.G.; COOMES, D.A Lines, E.R.; Morris, W.K.; RüGER, N.; Álvarez, E.; Blundo, C.; Bunyavejchewin, S.; Chuyong, G.; Davies, S.J.; Dugue, A.; EwanGo, C.N.; Flores, O.; Franklin, J.F.; Grau, H.R.; Hao, Z.; Harmon, M.E.; Hubbell, S.P.; KenFACK, D.; Lin, Y.; MaKana, J.R.; Malizia, A. Malizia, L.R.; PabST, R.J.; PongPatTananURaK, N.; Su, S.H.; Sun, I.F.; Tan, S.; ThOMaS, D.; van Mantgem, P.J.; Wang, X.; Wiser, S.K. \& Zavala. M.A. 2014. Rate of tree carbon accumulation increases continuously with tree size. Nature, 507.

Sverdrup-Thygeson, A.; SøgaArd, G.; Rusch, G.M. \& BARTON, D.N. 2014. Spatial Overlap between Environmental Policy Instruments and Areas of High Conservation Value in Forest. PLoS ONE 9(12): e115001.

Tapia, R.; Alcañz, J.M; Moya, B; Moya, J.; Plumed, J.; Sánchez, M.; Placios, C-J. \& Prada, O. 2015 Árboles singulares de la España interior. Fundación Félix Rodríguez de la Fuente. Departamento de Árboles Monumentales de IMELSA.

UradníčeK, L.; Sramek, M. \& Dreslerova, J. 2017. Checklist of champion trees in the Czech Republic. $J$. Landsc. Ecol., 10: 109-120.

Vannuccini, M.; Giachini, M., Giorgi, D. \& Ferretti, R. 2006. Monumental trees inventories at different scales: objectives and perspectives. $9^{\circ}$ Fórum Europeu de Floresta Urbana. (EFUF) - Urban Forestry Bridges, 22-27 maio Florença, Itália. Disponível em<http://www.studioeureco.com/wp-content/ uploads/2012/01/Vannuccini EFUF 2006.pdf>, dezembro de 2018.

VAN Hoecke, Mark. 2015. Methodology of comparative legal research. Law and method, 1-35.

Zhang, H.; LaI, P.Y. \& JiM, C.Y. 2017. Species diversity and spatial pattern of old and precious trees in Macau. Landsc. Urban Plan. 162, 56-67. 